\title{
Multiwavelength comparison of modeled and measured remote tropospheric aerosol backscatter over Pacific Ocean
}

\author{
D. R. Cutten, ${ }^{\text {R R. F. Pueschel, }}{ }^{2}$ D. A. Bowdle, ${ }^{1}$ V. Srivastava,${ }^{3}$ A. D. Clarke, ${ }^{4}$ \\ J. Rothermel, ${ }^{5}$ J. D. Spinhirne, ${ }^{6}$ and R. T. Menzies ${ }^{7}$
}

\begin{abstract}
Aerosol concentrations and size distributions in the middle and upper troposphere over the remote Pacific Ocean were measured with a forward scattering spectrometer probe (FSSP) on the NASA DC-8 aircraft during NASA's Global Backscatter Experiment (GLOBE) in May-June 1990. The FSSP size channels were recalibrated based on refractive index estimates from flight-level aerosol volatility measurements with a collocated laser optical particle counter (LOPC). The recalibrated FSSP size distributions were averaged over 100 -s intervals, fitted with lognormal distributions and used to calculate aerosol backscatter coefficients at selected wavelengths. The FSSP-derived backscatter estimates were averaged over 300 -s intervals to reduce large random fluctuations. The smoothed FSSP aerosol backscatter coefficients were then compared with LOPC-derived backscatter values and with backscatter measured at or near flight level from four lidar systems operating at $0.53,1.06,9.11,9.25$, and $10.59 \mu \mathrm{m}$. Agreement between FSSP-derived and lidar-measured backscatter was generally best at flight level in homogeneous aerosol fields and at high backscatter values. FSSP data often underestimated low backscatter values especially at the longer wavelengths due to poor counting statistics for larger particles ( $>0.8 \mu \mathrm{m}$ diameter) that usually dominate aerosol backscatter at these wavelengths. FSSP data also underestimated backscatter at shorter wavelengths when particles smaller than the FSSP lower cutoff diameter $(0.35 \mu \mathrm{m})$ made significant contributions to the total backscatter.
\end{abstract}

\section{Introduction}

Tropospheric aerosols which lie above the planetary boundary layer (PBL) have in the past 15 years become an important subject of research for space-borne measurements of winds in this region of the atmosphere. Currently only sparse data are available on tropospheric winds over remote ocean areas and passively borne aerosols are a surrogate to determine wind fields over this region using a space-based Doppler lidar system [Menzies, 1986; Baker et al., 1995]. However, the aerosol properties useful for wind measurements in these regions have not been extensively studied. Rothermel et al. $[1989 ; 1995$ a] reported a low background backscatter mode in the middle and upper troposphere based on statistical reanalysis of infrared ground-based lidar climatological measurements

\footnotetext{
IInstitute for Global Change Research and Education and Earth System Science Laboratory, University of Alabama. Huntsville. Alabama.

${ }^{2}$ NASA Ames Research Center, Moffetl Field, California.

3 Institute for Global Change Research and Education and Universities Space Research Association, Huntsville, Alabama.

${ }^{4}$ School of Oceanography. University of Hawaii, Honolulu, Hawaii.

${ }^{5}$ NASA Marshall Space Flight Center. Huntsville. Alabama.

${ }^{6}$ NASA Goddard Space Flight Center, Greenbelt, Maryland.

${ }^{7}$ Jet Propulsion Laboratory, Pasadena. Califomia.
}

Copyright 1996 by the American Geophysical Union. made over a number of years over Colorado and airborne Doppler lidar measurements over the United Kingdom. The weak magnitude of this background aerosol mode would pose a stringent lest on the effectiveness of any satellite-borne Doppler laser wind sensor system to provide tropospheric wind data (D. A. Bowdle et al., unpublished data, 1995).

Instrumentation which measures aerosol propertics is diverse. Several types of sensors are required to measure unambiguously a synergistic set of aerosol properties [Prospero et al., 1983]. For example, pulsed lidar systems can measure aerosol backscatter coefficient above or below flight level but only provide limited data on the aerosol size distributions if several wavelengths are used simultaneously. Detailed, realtime aerosol size distribution data are obtained primarily using optical particle counters, which can be used with measured aerosol composition to predict aerosol backscatter at flight level. When different sensors are used in this way, direct comparison with measured aerosol backscatter data is required for corroboration, particularly where low aerosol concentrations prevail. To obtain data to guide design and performance studies of prospective satelite Doppler wind lidar, NASA conducted the Global Backscatter Experiment (GLOBE) survey mission flights in November-December 1989 (GLOBE I) and May-June 1990 (GLOBE II) to sample the free troposphere aerosol in the Pacific basin [Bowdle et al., 1991]. This area was selected because of the possible extensive occurrence of the background aerosol backscatter mode in the midtropospheric region. The GLOBE II instrumentation aboard the NASA DC-8 aircraft consisted of optical particle counters sampling at flight level and several lidar systems to measure aerosol 


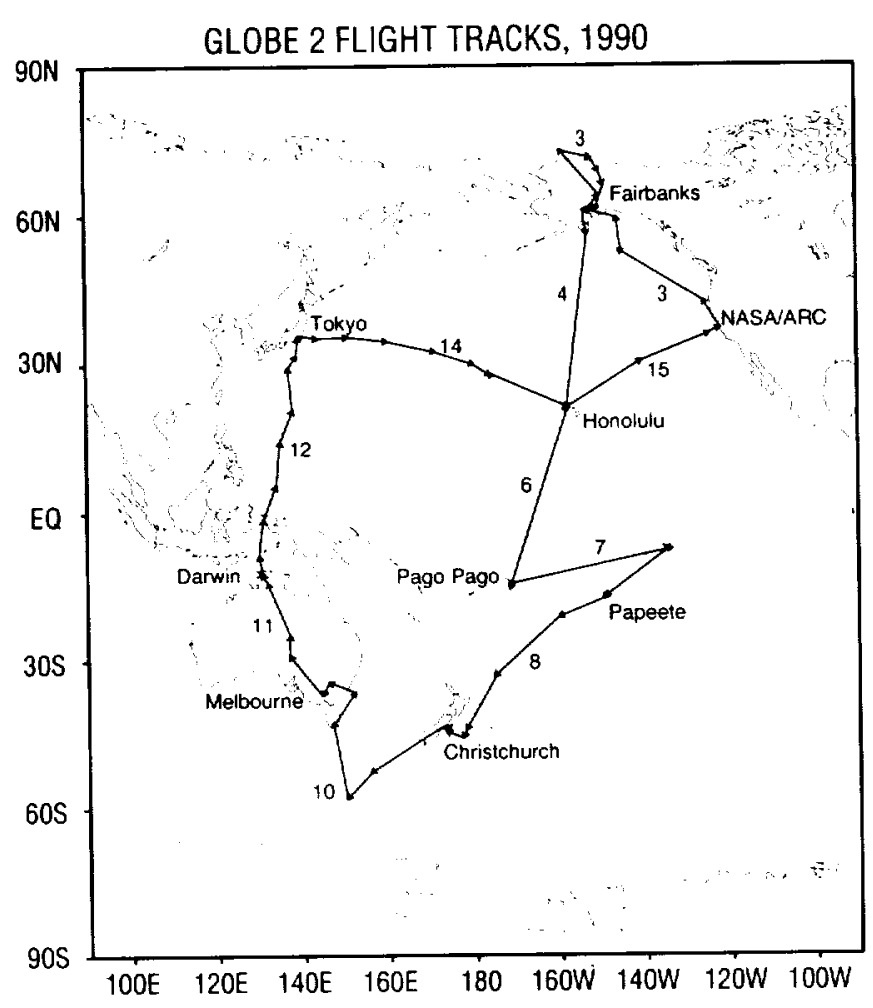

Figure 1. Flight paths for all transit flights made during NASA's GLOBE II May-June 1990 Pacific survey mission.

backscatter coefficient at or near flight level for several wavelengths.

This paper will report on selected aspects of the aerosol backscatter coefficient $\left(\beta, \mathrm{m}^{-1} \mathrm{sr}^{-1}\right)$ data obtained in the second survey mission of GLOBE. In particular, the comparison is reported between backscatter coefficient data computed from NASA Ames Research Center (ARC) forward scattering spectrometer probe (FSSP) size distribution data and that measured with four lidar systems operating at $0.53-$, 1.06-, 9.11-, 9.25-, and $10.59-\mu \mathrm{m}$ wavelengths. Discrepancies are explained by instrument performance characteristics and by spatial variability in aerosol microphysics and composition at or near flight level. The results are used to determine the finest temporal resolution that can be achieved in a wide variety of atmospheric conditions for aerosol backscatter values derived from FSSP measurements.

\section{Experimental Details}

All data reported here were taken aboard the NASA DC- 8 aircraft on the GLOBE II Pacific basin survey mission during May-June 1990 [Bowdle et al., 1991]. Figure 1 shows the transit flight tracks flown, most of which were made near altitudes of 8 and $12 \mathrm{~km}$. Several local flights also were made and these generally consisted of stepped ascents and descents. In this paper the analysis will concentrate on (1) data from two case studies (transit flights 6 and 14) and (2) combined data from flights $6,8,10,12$, and 14. GLOBE instruments can be grouped into two classes: those measuring aerosol backscatter coefficient $\beta$ (lidars) and those measuring selected aerosol microphysical properties (optical particle counters) ( $\beta$ is the volume angular scattering at $180^{\circ}$ from a particulate medium per unit length of the irradiating beam, per steradian centered about the direction of the incident beam). These instruments are briefly described in the following sections. Table 1 shows the typical sample volume for each sensor described when the aircraft is flying at $200 \mathrm{~m} \mathrm{~s}^{-1}$ with an integration time of $100 \mathrm{~s}$ and its relationship to the aircraft.

\subsection{Optical Particle Counters}

Optical particle counters were the primary instruments used on the DC- 8 aircraft to measure the concentrations and size distributions of aerosols at flight level. The FSSP-300 probe, which provided data for the main analysis in this paper, was manufactured by Particle Measuring Systems, Incorporated (PMS). The probe is designed to measure in situ size distributions with fine temporal resolution in linearly distributed size bins over a 0.35 - to $20-\mu \mathrm{m}$ diameter range [Baumgardner et al., 1992; Pueschel et al., 1994]. The FSSP pod unit was mounted on the extremity of the right wing. In-flight data (counts/bin) were recorded at 1 -s intervals and later converted to sizedistributed concentrations averaged over 10 -s intervals. The instrument was calibrated for size bin accuracy using monodisperse latex spheres. Sampling efficiency was assumed to be unity. Baumgardner et al. [1992] have estimated the

Table 1. Comparison of GLOBE Sensor Sample Volumes

\begin{tabular}{|c|c|c|c|c|c|c|}
\hline Sensor & $\begin{array}{c}\text { Laser } \\
\text { Wave- } \\
\text { length, } \\
\mu \mathrm{m}\end{array}$ & $\begin{array}{c}\text { Lidar } \\
\text { Pulse } \\
\text { Rate, } \\
\mathrm{Hz}\end{array}$ & $\begin{array}{c}\text { Lidar Vertical } \\
\text { Integration, } \\
\text { m }\end{array}$ & $\begin{array}{c}\text { Beam } \\
\text { Area, } \\
\mathrm{m}^{2}\end{array}$ & $\begin{array}{l}\text { Sample Volume } \\
\text { Relative to } \mathrm{A} / \mathrm{c}\end{array}$ & $\begin{array}{c}\text { Sample } \\
\text { Volume, } \\
\mathrm{m}^{3}\end{array}$ \\
\hline JPL lidar & 9.25 & 4 & 150 & 1 & nadir or zenith & $6 \times 10^{4}$ \\
\hline GSFC lidar & $\begin{array}{l}0.53 \\
1.06 \\
1.54\end{array}$ & 50 & 75 & 1 & nadir or zenith & $4 \times 10^{5}$ \\
\hline $\begin{array}{l}\text { MSFC CW } \\
\text { lidars }^{\dagger}\end{array}$ & $\begin{array}{r}9.11 \\
10.59\end{array}$ & - & - & $3 \times 10^{-2^{*}}$ & $\begin{array}{l}50 \mathrm{~m} \text { from RHS } \\
\text { of } \mathrm{A} / \mathrm{c}\end{array}$ & $6 \times 10^{2}$ \\
\hline $\mathrm{FSSP}^{\dot{T}}$ & - & - & - & $5 \times 10^{-8}$ & RHS wing pod & $1 \times 10^{-3}$ \\
\hline LOPC & - & - & - & $1 \times 10^{-6}$ & A/c entry nozzle & $1.7 \times 10^{-3}$ \\
\hline
\end{tabular}

GLOBE, 100-s integration time is used for all sensors.

*Assumes a 5-m lidar beam focus depth, $50 \mathrm{~m}$ from the aircraft.

${ }^{\dagger}$ Calculations based on an aircraft speed of $200 \mathrm{~m} \mathrm{~s}^{-1}$.

$\stackrel{+}{*}$ tlow rate of $17 \mathrm{~cm}^{3} \mathrm{~s}^{-1}$ with virtual impactor. 
Table 2. Threshold Levels and Uncertainties for Lidar Measured $\beta$

\begin{tabular}{lccc}
\hline \multicolumn{1}{c}{ Lidar } & Wavelength, $\mu \mathrm{m}$ & $\begin{array}{c}\text { Threshold } \beta \text { Level, } \\
\mathrm{m}^{-1} \mathrm{sr}^{-1}\end{array}$ & $\beta$ Uncertainty \\
\hline GSFC pulsed & 0.53 & $5 \times 10^{-9}$ & $\pm 1 \times 10^{-8}$ \\
GSFC pulsed & 1.06 & $1 \times 10^{-9}$ & $\pm 1 \times 10^{-9}$ \\
MSFC CW & 9.11 & $6 \times 10^{-12}$ & $\pm 0.72 \times 10^{-12^{*}}$ \\
JPL pulsed & 9.25 & $1 \times 10^{-11}$ at $2 \mathrm{~km}$ & $\pm 2 \times 10^{-11}$ \\
& & from A/c & \\
MSFC CW & 10.59 & $2 \times 10^{-11}$ & $\pm 0.24 \times 10^{-11^{*}}$ \\
\hline
\end{tabular}

*Using surface acoustic wave (SAW) signal processing.

uncertainty in the total number concentration measured by the FSSP as $25 \%$ assuming a sampling error of $10 \%$.

The second system, a thermally preconditioned laser optical particle counter (LOPC) developed by the University of Hawaii [Clarke, 1991] provided size-segregrated information on the aerosol physicochemistry in near real time. A PMS laser aerosol spectrometer (model LAS-X) was modified to provide 256 channels of equal logarithmic width for particle diameters from 0.15 to $7.0 \mu \mathrm{m}$. A virtual impactor (VI) upstream of the LOPC is employed to increase the concentrations of the larger particles greater than $0.5 \mu \mathrm{m}$ diameter. The preheater system interfaced with the LOPC, in turn, heated the aerosol to $40^{\circ} \mathrm{C}$, $150^{\circ} \mathrm{C}$, and $300^{\circ} \mathrm{C}$. This allowed size-resolved measurements of sulfuric acid, ammonium sulfate, ammonium bisulfate, and refractory (e.g., dust, soot) aerosols to be obtained based on their volatility at these temperatures. Aerosol for sampling by the LOPC was bought into the aircraft through a blunt entry nozzle diffuser. Flow rate was maintained at isokinetic values based on measured flows and corrected for tube pressure, temperature, and large-particle loss [Porter et al., 1992]. LOPC data were obtained in flight by alternately directing the sample flow through each preheater channel without the VI and
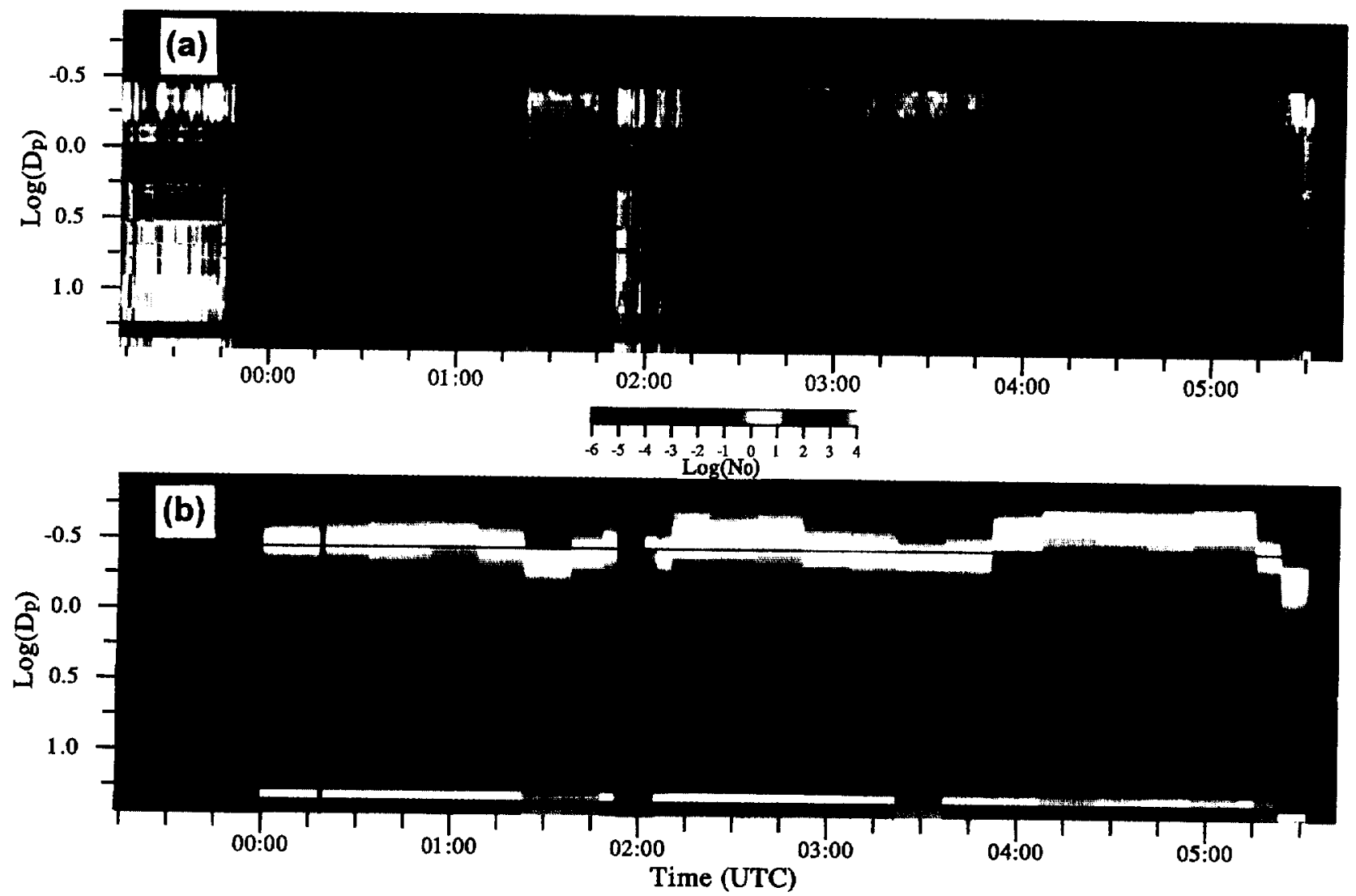

Plate 1. False color cross section of $\log \left(d n / d \log \left(D_{p}\right)\right)$ for 7 ight 14 derived from coregistered (a) 20-s forward scattering spectrometer probe (FSSP) recalibrated and (b) laser optical particle counter (with virtual impactor) sensor data. Line at $\log _{10}(0.39)$ in Plate $\mathrm{lb}$ corresponds to lower diameter limit for the recalibrated FSSP sensor. Note that diameter range $(0.15$ to $20 \mu \mathrm{m})$ and $d n / d \log \left(D_{p}\right)$ range $\left(10^{-6}\right.$ to $\left.10^{4} \mathrm{~cm}^{-3}\right)$ are both in logarithmic units. In Plate la the bar at the bottom gives the integrated particle numbers over $0.35-20 \mu \mathrm{m}$, while the two bars in Plate $1 \mathrm{~b}$ cover size ranges $0.16-7 \mu \mathrm{m}$ and $0.39-7 \mu \mathrm{m}$, respectively. 
through the $40^{\circ} \mathrm{C}$ and $300^{\circ} \mathrm{C}$ channels with the VI. Several complete cycles were performed during a typical 10- to 15 -min integration period to avoid confusing temporal variability with aerosol volatility. These sample periods were usually divided equally among the five preconditioning channels, so the total sample time in each channel was about 2-3 min. The LOPC was calibrated for sizing accuracy and constituent discrimination using well-characterized, laboratory-generated monodisperse particles with compositions similar to atmospheric aerosols.

\subsection{Lidars}

The lidar instrument complement to measure aerosol backscatter coefficients $\beta$ directly consisted of four lidar systems operating at six wavelengths. Each of these systems (two pulsed and two continuous) will be briefly described. Table 2 summarizes the threshold level and uncertainty in $\beta$ measured by each lidar.

The two continuous-wave ( $\mathrm{CW}$ ) coherent Doppler lidar systems (operating at wavelengths of $9.11 \mu \mathrm{m}$ and $10.59 \mu \mathrm{m}$ ) were developed by NASA/Marshall Space Flight Center (MSFC) [Rothermel et al., 1995b]). Both beams were focused at about $50 \mathrm{~m}$ from the aircraft right-hand side with a typical sample volume of $600 \mathrm{~m}^{3}$ (Table 1). Detection sensistivity for the $9.11-\mu \mathrm{m}$ and $10.59-\mu \mathrm{m}$ lidars was $\approx 6 \times 10^{-12} \mathrm{~m}^{-1} \mathrm{sr}^{-1}$ and 2 $\times 10^{-11} \mathrm{~m}^{-1} \mathrm{sr}^{-1}$, respectively. These sensistivity levels are mean values derived from an ensemble of signal-to-noise ratio data encompassing all GLOBE Il flights. Thus the actual detection level within a particular flight may vary around these values. The lidar output signals were processed using two different data systems as described by Rothermel et al., [1995b]. Both $\mathrm{CW}$ lidars also have been rigorously calibrated [Jarzembski et al., 1995] using two different techniques that give internal consistency.

The pulsed $\mathrm{CO}_{2}$ coherent lidar system developed by NASA Jet Propulsion Laboratory (JPL) [Menzies and Tratt, 1994] used a single wavelength of $9.25 \mu \mathrm{m}$. Beam direction was selectable between either zenith or nadir positions. Pulse rate was $4 \mathrm{~Hz}$. Data were stored on a pulse-by-pulse basis at a rate corresponding to $15-\mathrm{m}$ range resolution, although the pulse length degraded the effective lidar range resolution to about $100 \mathrm{~m}$. These data were later edited, integrated over $100 \mathrm{~s}$, and smoothed vertically over $150-\mathrm{m}$ range increments. Detection sensitivity was $\approx 10^{-11} \mathrm{~m}^{-1} \mathrm{sr}^{-1}$ at 1 to $2 \mathrm{~km}$ from the aircraft.

The second pulsed lidar system (developed by NASA Goddard Space Flight Center (GSFC) [Spinhirne et al., 1991] was based on a Nd:YAG laser operating at a fundamental wavelength of $1.06 \mu \mathrm{m}$. Raman shifting of the fundamental wavelength provided the $1.54-\mu \mathrm{m}$ transmitted pulse, while frequency doubling of the same wavelength gave the $0.532-\mu \mathrm{m}$ pulse. Beam direction was selectable between either zenith or nadir positions. Pulse rate used was $50 \mathrm{~Hz}$ and a range resolution of $75 \mathrm{~m}$ selected. Aerosol backscatter threshold sensistivity at $1.06 \mu \mathrm{m}$ and $0.53 \mathrm{~mm}$ was $1 \times 10^{-9} \mathrm{~m}^{-1} \mathrm{sr}^{-1}$ and $5 \times$ $10^{-9} \mathrm{~m}^{-1} \mathrm{sr}^{-1}$, respectively. Since Rayleigh backscatter can be of the order of or greater than the aerosol backscatter, this component was removed. Temperature profiles were used from the gridded National Meteorological Center model output closest to the lidar observation time and location [Spinhirne et al., 1991]. These profiles were considered the best available at the time.

\section{Data Reduction and Analysis Procedures}

This section deals primarily with the preprocessing of the FSSP size distribution data, e.g., examining data quality, recalibrating the size bin edges, accommodating poor count statistics, and smoothing. To handle large quantities of FSSP and LOPC size distribution data efficiently, data visualization techniques were applied on a flight-by-flight basis. The computer software used was the JPL LinkWinds data visualization and analysis program [Jacobson et al., 1994], which can display data, after being suitably formatted, in a time-size crosssection plot with a false color display of the parameter of interest. Sample images of aerosol number in each size interval as a function of time are shown in Plate la (FSSP) and Plate Ib (LOPC) for the Japan to Hawaii transit flight 14. Data displays in this format clearly showed any anomalous instrument responses. Any such problems were corrected and reveri-

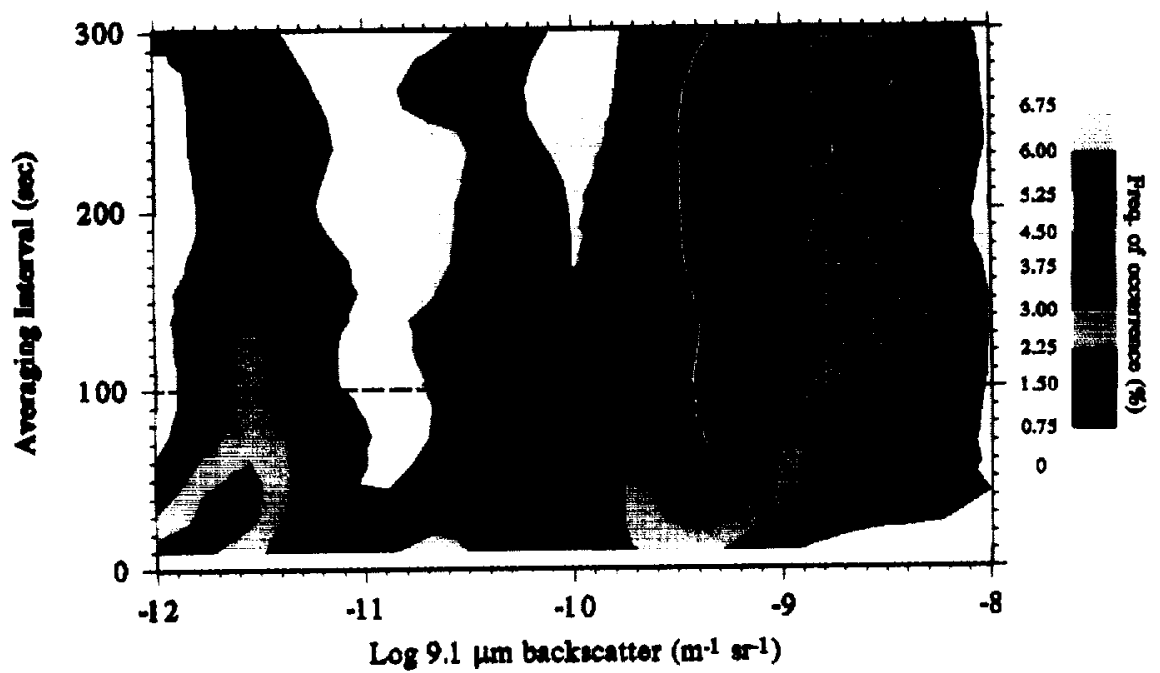

Plate 2. Contour plot of frequency of occurrence (percent) of FSSP-derived 9.11- $\mu \mathrm{m}$ aerosol backscatter as a function of FSSP dn/d $\log D_{p}$ averaging time for flight 14. 
fied by comparing the two sets of data. These displays were also used to identify regions with unusual aerosol properties by verifing that both instruments observed similar features. One exception to this was when the aircraft flew through cloud. The FSSP continued to make measurements, while the LOPC was usually tumed off. This can be seen in Plate 1 prior to 0000 and around 0200 UTC.

\subsection{LOPC}

Raw LOPC data were converted to concentration as a function of size for each channel. Corrections were applied for losses of large particles in the inlet plumbing and for gains of large particles in the virtual impactor (e.g., net gains of about a factor of 10 at $3 \mu \mathrm{m}$ diameter [Porter et al., 1992]). The corrected distributions were smoothed over several size bins to reduce counting noise. Differences in the size distributions among the various preconditioning channels were used to derive size-distributed concentrations for sulfuric acid, ammonium sulfate/bisulfate, and refractory materials assuming that these constituents were externally mixed [Clarke, 1991, 1993; V. Srivastava et al., manuscript in preparation, 1995]. Data from the VI channel were used wherever possible in these computations because of their improved count statistics for larger particles. Results integrated over all particle sizes typically showed a molar ratio of ammonium to sulfate near 0.3 [Clarke, 1993]. This value indicates a sulfuric acid/ammonium bisulfate mixture, referred to hereinafter as acid sulfate.

The measured size distributions were then corrected for condensed water that had evaporated between the ambient and the LOPC optical sensor, since the relative humidity in the sample volume was less than $10 \%$. Ambient relative humidities in the troposphere (derived at flight level from a frost point hygrometer) generally varied from 10 to $70 \%$. Water amounts were estimated using growth rules for acid sulfate particles [Tang, 1980], assuming growth under nonfreezing conditions. (Observational evidence [Pueschel et al., 1994] suggested that sulfate particles are probably supersaturated droplets at the temperatures encountered in these flights and hence remain unfrozen). Particle growth amounted to a factor of $\approx 1.1$ at $70 \%$ relative humidity. Estimated uncertainty in $\mathrm{D} / \mathrm{D}_{0}$ over measured relative humidity range is of the order of \pm 0.05 . Refractive index data for acid sulfate (which was set by the constant molar ratio) and water were combined using standard volumetric mixing rules. This allowed the real and imaginary aerosol refractive index to be derived at $0.55-, 1.06-9.11-$, and $10.59-\mu \mathrm{m}$ wavelengths. Since $9.11-$ and $9.25-\mu \mathrm{m}$ wavelengths are very close and refractive index variations between them generally small, no $9.25-\mu \mathrm{m}$ values were calculated. The derived refractive index values for each LOPC sample period were used to recalibrate the FSSP size distributions for that same period and to support the recalibrated FSSP data in backscatter computations at $1.06,9.11$, and $10.59 \mu \mathrm{m}$ (section 3.2). Estimates of the aerosol growth and refractive index were not used in regions where the FSSP or the CW lidars indicated cloud, which would interfere with the LOPC data acquisition, or in highly variable aerosol conditions, which would interfere with the LOPC data processing.

Doing a propagation of error calculation for ammonium sulfate composition gives a square root of the sum (rss) of all uncertainties in derived visible backscatter of $15 \%$ at $\mathrm{RH}=$ $15 \%$ and $25 \%$ at $\mathrm{RH}=70 \%$. In some instances, sampling statistics could increase the rss value. Furthermore, the use of a constant molar ratio and a constant growth factor across the
LOPC size range could also lead to an error increase. For example, growth can be overestimated for large refractory particles (dust) which are treated as if they were completely soluble. These errors will likely be greatest in high relative humidity because of the substantial aerosol growth under these conditions. Further work is being done to improve the physicochemical model by determining the molar ratio and refractive index independently for each size bin (V. Srivastava et al., manuscript in preparation, 1995). The size distributions and refractive index inputs from the improved LOPC aerosol model were used in this paper to calculate aerosol backscatter at the same lidar wavelengths used in the FSSP modeling study.

\subsection{FSSP}

The original FSSP size distribution data were measured with the probe calibrated using latex spheres (refractive index of $1.585-0 i$ at the $0.63-\mu \mathrm{m}$ He: Ne laser wavelength). This value of refractive index is higher than that usually found for acrosols composed of sulfuric acid, ammonium sulfate, or dust whose real parts lie in the range 1.4 to 1.5. The original FSSP sensor calibration would then lead to size distributions with generally lower sizes and artifacts around the resonant region (0.8-1.0 $\mu \mathrm{m}$ diameter). Simulations of a similar sensor, the PMS active scattering acrosol spectrometer probe (ASASP$100 \mathrm{X}$ ), were shown to greatly distort the returned size distribution if the correct refractive index is not used [ $\mathrm{Kim}, 1995]$. The distortion was greatest in the resonant region of the instrument's response corresponding to 0.4 - to $0.8-\mu \mathrm{m}$ particle diameter. Strapp et al., [1992] also reported that calibration changes need to be taken into account for the FSSP-300 when hygroscopic acrosols are measured in high relative humidities. Therefore the FSSP size bin limits were recalibrated using refractive index data (for $0.55 \mu \mathrm{m}$ ) derived from thermally segregated LOPC size distribution data (see section 3.1 ). The FSSP calibration procedure is based on Pinnick et al. [1981] where Lorenz-Mic calculations of the instrument's response were done using the new refractive index data for each flight. (Note that the differences in refractive index for wavelengths 0.55 and $0.63 \mu \mathrm{m}$ are considered very small.) Typically, a single refractive index value is derived for each LOPC sampling period in a flight, and so the FSSP size bin edges are corrected using a constant refractive index over each of these periods. Bin edge corrections amounted to less than $0.1 \mu \mathrm{m}$ in the submicron size range up to $0.5 \mu \mathrm{m}$ above this size range.

Once the $10 \mathrm{~s}$ basic FSSP size distribution data are recalibrated, "boxcar" averaging is performed. The choice of averaging period needs to be carefully considered. Patterson and Bowdle [1991] examined the effect of averaging aerosol backscatter coefficient derived from the small sampling volume of an earlier FSSP unit. They found from log-probability plots that as the averaging period went from their basic $1-\mathrm{min}$ period to 10-min time resolution, the importance of the small tail in the backscatter distribution diminished and the backscatter became more lognormally distributed. That part of the cumulative probability curve above $50 \%$ showed little change. The major changes in the lower part of the curve occurred when going from 1 -min to 5 -min averages. In this analysis a slightly different approach is taken. For each GLOBE Il flight a contoured frequency of occurrence (percent) plot of aerosol backscatter coefficient $\beta$ (calculated at $0.1 \mathrm{log}$ $\beta$ intervals) versus averaging interval at $9.11-\mu \mathrm{m}$ wavelength is made. An example is shown in Plate 2 for the Japan to 
Hawaii transit flight (flight 14). This contour plot indicates that for averaging periods between $20 \mathrm{~s}$ and $50 \mathrm{~s}$ the frequency of occurrence of $\beta$ values shows a strong tail below $1.5 \times$ $10^{-12} \mathrm{~m}^{-1} \mathrm{sr}^{-1}$ which recedes after the averaging period exceeds $50 \mathrm{~s}$. The presence of this small tail initially indicates an artifact arising from the use of too small of a sampling volume where insufficient particles in certain size bins are not sampled adequately. This is consistent with the results presented by Patterson and Bowdle after applying a wavelength conversion of 0.33 to obtain $10.6-\mu \mathrm{m}$ backscatter data. Averaging periods above $100 \mathrm{~s}$ reveal that the shape of the mode at high backscatter is mostly independent of averaging period. Similar trends in contour plots from several other GLOBE II flights suggest an optimal averaging period of $100 \mathrm{~s}$.

The next step in the data processing is to fit a monomodal lognormal curve to the $100 \mathrm{~s}$ averaged $d n / d \log \left(D_{p}\right)$ data. In the troposphere, particles formed from smaller particles by coagulation or by condensation of vapors, involve statistical fluctuations, and the resulting size distribution can be described by a lognormal distribution [Horvath et al., 1990]. Approximating the measured data with a modeled curve has two advantages. First, large statistical fluctuations will be appropriately weighted in bins with low counts $(0,1$, and 2 , ...) at the larger size ranges $(>1 \mu \mathrm{m})$. This approach reduces some of the large high-frequency fluctuations that would otherwise characterize backscatter estimates from the FSSP data. Second, the effect of multivalued response (artificial bumps and knees in the data [Pinnick et al., 1981] occurring in the $1-$ to $2-\mu \mathrm{m}$ and $4-108-\mu \mathrm{m}$ diameter regions) can be minimized without resorting to bin amalgamation and subsequent loss of size resolution. The curve fitting is implemented with a least squares technique whose quality can be assessed by comparing the goodness of fit for the normalized number distribution and the normalized volume distribution and intercomparing the two as reported by Horvath ef al. [1990]. The quality of the final fitting is also indicated by the correlation coefficient, which in many cases is above 0.98 .

A number of FSSP $d v / d \log \left(D_{p}\right)$ plots trom several flights were examined and found to exhibit a single-mode structure. Theretore it was assumed in this analysis that the size distributions above $0.35 \mu \mathrm{m}$ diameter were single mode since most of the measurements were made in the cloud-free troposphere. For the dust regime sampled near Tokyo, Japan, the monomodal shape of the size distributions was not significantly degraded where a single lognormal curve would not be appropriate. However, when cloud was encountered at flight level, the curve fitting did not perform very well; the size data were flagged so that no backscatter calculations were done with these data. (Also backscatter calculations for clouds required a different refractive index which the LOPC-derived indices may not reflect, because it was generally switched off when flying through (loud.) Geometric mean diameter for number distributions generally fell between 0.4 and $0.7 \mu \mathrm{m}$ and the geometric standard deviation between 1.4 and 1.8 . Size distributions with geometric mean diameter $<0.1 \mu \mathrm{m}$ and $>1.5 \mu \mathrm{m}$ and correlation coefficients equal to zero or negative were also flagged and omitted from the backscatter calculation. It should be noted that the mode diameters derived from the FSSP data were significantly larger than those derived from the LOPC data, due to differences in the small-particle detection thresholds for the two instruments. Pueschel et al. [1994] summarizes the effects of small and large ammonium sulfate particle contributions to the acrosol backscatter coefficient, as a function of wavelength. (Using ammonium sulfate instead of an acid sulfate composition would not significantly change the small-particle contribution.) For infrared wavelengths, contribution from the small diameter size range $(<0.35 \mu \mathrm{m})$ amounts to less than $1 \%$. However, for the 1.06- and $0.53-\mu \mathrm{m}$ wavelengths the aerosol backscatter coefficient can be underestimated by as much as $22 \%$ and $33 \%$, respectively.

Finally, the calculated 100 -s aerosol backscatter coefficient data are subjected to a running average using \pm 1 data points either side of the 100-s time point. It is found (see section 4) that there are many times when bin counts were not recorded above $1 \mu \mathrm{m}$ diameter during periods of low aerosol numbers and, consequently, the acrosol backscatter coefficient fluctuated widely even after the size data were fitted with an analytical curve. Using a "boxcar" average with a 300 -s period did not smooth out the large backscatter fluctuations where the corresponding coregistered $\mathrm{CW}$ lidar backscatter data indicated minimal fluctuation. By doing a running average on the FSSPderived aerosol backscatter, the larger fluctuations were considerably reduced with little loss of physical features.

\section{Results and Discussion}

\subsection{Aerosol Number Comparison}

Statistical theory requires that FSSP particle counting obey Poisson statistics if the particle count from a given size bin is to be representative of the acrosol sample. FSSP count data from several flights were examined during periods of low infrared backscatter and were tested against a null hypothesis that counts in a particular size bin obey Poisson statistics. In most cases the counts were found to be not significant at the $5 \%$ confidence level for size bins corresponding to $0.8 \mu \mathrm{m}$ or above. Below this size the particle counts were generally significant giving the FSSP good count statistics. Therefore to independently assess this finding, particle number concentrations from the FSSP and LOPC size distribution data were compared for particle diameters greater than $0.8 \mu \mathrm{m}$. To make this comparision, the FSSP $d n / d \log \left(D_{p}\right)$ data are averaged over a LOPC sampling period. During a LOPC in-flight sampling period, each of the five channels was selected for about a minute resulting in a particular channel having a total sampling time of 2-3 min over a 10 - to 15 -min LOPC period. Hence, the averaging period for the FSSP data is about 5 times longer than an individual LOPC channel period. This approach was taken because the start and end times for the individual channels were not available during the LOPC sampling period. The LOPC volume sampling rate was about 1.7 times larger than the effective FSSP sampling rate and, with the virtual impactor (channel 4) in line, provided an additional gain of about 3 and 9 at size bins $I$ and $3 \mu \mathrm{m}$, respectively, for $12 \mathrm{~km}$ altitude [Porter ef al., 1992]. Considering all of these effects (including plumbing losses), the LOPC VI channel provides an effective sample volume of $\approx 16$ times larger than the FSSP for the larger particles $(\approx 3 \mu \mathrm{m})$. Note that this factor will increase at lower altitudes. The disparity in sample volumes was even greater when backscatter values were computed from 100-s FSSP samples instead of the 10- to 15-min LOPC samples.

It was essential that these comparisons be limited to nearhomogeneous aerosol regimes, so the LOPC and FSSP data were selected for comparison where $\mathrm{CW}$ lidar backscatter vari- 
ance was minimal and no cloud encountered. Figure 2 shows examples of LOPC (VI) versus FSSP $d n$ plots from four suitably homogeneous regions on three GLOBE II transit flights (flights 6, 8, and 14): the $d n$ for each sensor are derived from integrating the respective averaged $d n / d \log \left(D_{p}\right)$ data over the diameter ranges $0.8-1.0 \mu \mathrm{m}, 1-2 \mu \mathrm{m}$, and 2-3 $\mu \mathrm{m}$. The maximum number of plotted data points for a given size range is determined by the number of LOPC sampling periods occurring in the three selected time periods, e.g., four in flight 6 and five in flight 14. Generic estimates were made of FSSP $d n$ values that corresponded to $N=1,10$, and 100 total particle counts using the relationship $d n / d \log \left(D_{p}\right)^{*} \Delta \log \left(D_{p}\right)=N / K \Delta t$. (K is the FSSP effective volume sampling rate which varies with aircraft speed, and $\Delta t$ is the sampling period.) Figure 2 shows three scales (one for each size group) where each decade count level occurs with respect to the $d n$ scale. Binomial count statistics imply that for a $50 \%$ probability of getting a count and a required minimum accuracy of $\pm 33 \%$, the total counts in the sampling period need to be above 10. Also the case of small number of counts, the binomial distribution would suggest the likelihood of undercounting occurring rather than overcounting.

Data for the smallest size grouping $(0.8-1.0 \mu \mathrm{m})$ in Figure 2 indicate a nominal 1:1 comparison. These data are mostly associated with high FSSP counts. Even below 10 counts there is only a weak bias toward the FSSP undercounting. For the 1to $2-\mu \mathrm{m}$ diameter range, $d n$ data from all three flights lie above the 1:1 line showing a clear bias to FSSP undercounting. There is a suggestion that the bias increases as the count rate decreases toward unity, with bias factor ranging from five to eight. The 2- to $3-\mu \mathrm{m}$ diameter range showed mixed results; five of the compared $d n$ data show a bias. In this size range, relative humidity corrections, or correction for the large particle loss to the LOPC particle size, may introduce additional errors masking the FSSP undercounting.

The fact that the FSSP sensor is underestimating $d n / d$ log $\left(D_{p}\right)$ for particles above $1 \mu \mathrm{m}$ diameter is discussed further in the following section on infrared aerosol backscatter data comparisons. It is this size range that contributes greatest to

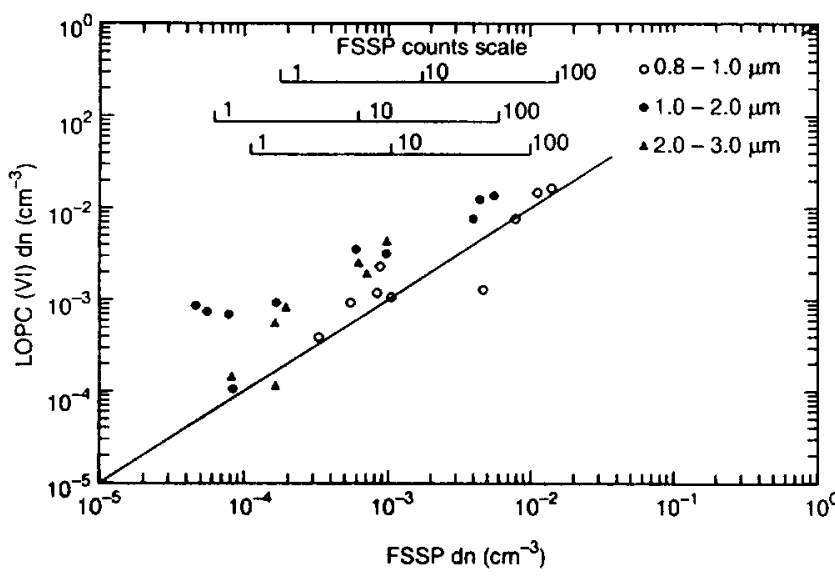

Figure 2. Cross plot of LOPC (with virtual impactor) $d n$ versus FSSP $d n$ data for three selected size ranges taken from flight 6, 0036-0154 UTC, flight 8, 0129-0208 UTC, and flight 14, 0300-0345 UTC and 0415-0445 UTC. Values of $d n$ corresponding to FSSP decade total particle counts are indicated at the top of the figure by the FSSP count scale for each size range. the differential aerosol backscatter coefficient at these wavelengths [Srivastava et al., 1992].

\subsection{Aerosol Backscatter Coefficient Comparisons: Case Studies}

Results presented here are based on transit flights 6 and 14 . Flight 6 was chosen as a representative of a meridional flight across the equatorial region, while flight 14 represents a zonal flight in the northern hemisphere.

Occasional breaks in the FSSP-derived $\beta$ shown in the time series plots for the two transit flights are the result of criteria applied to the lognormal fitting of the size distribution data, as discussed earlier. For example, no fitting is done when cloud was encountered because the appearance of a cloud particle mode made fitting a single-mode lognormal curve inappropriate: this study was confined to clear air aerosol backscatter. Since the 9.11 - and $9.25-\mu \mathrm{m}$ wavelengths are very close and refractive index variations between them were usually small, no backscatter computations were performed at $9.25 \mu \mathrm{m}$; the 9.11- $\mu \mathrm{m}$ FSSP-derived backscatter data, $\beta_{\text {(FSSP, 9.11), were used }}$ to compare with the $9.25 \mu \mathrm{m}$ pulsed JPL lidar backscatter,

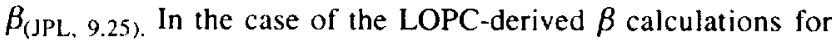
$0.53-, 1.06-, 9.11-$, and $10.59-\mu \mathrm{m}$ wavelengths the refractive index values were calculated using a physicochemical mixture model which determines the molar ratio for each size interval rather than a constant molar ratio across the whole size distribution. Hence, a growth factor was inferred that is more appropriate for that size and composition (V. Srivastava et al., manuscript in preparation, 1995). Aerosol backscatter data for several wavelengths from each of the two transit flights are now discussed.

\subsection{Hawaii to American Samoa Transit Flight}

Flight details. Flight 6 covered the leg from Honolulu, Hawaii, on a track south-southwest to Pago Pago, American Samoa (see Figure 1), on May 20-21, 1990, from 2105 to 0208 UTC with a constant pressure altitude maintained at approximately $8.5 \mathrm{~km}$ for the duration of the flight. At about 2130 UTC the aircraft encountered westerly winds which reached a maximum of $20 \mathrm{~m} \mathrm{~s}^{-1}$ at 2230 UTC, while at 2245 UTC, enhanced cloudiness and some convection was noted at flight level. This cloudiness was associated with a band of cloud to the east and northeast which could have had frontal characteristics. At 2300 UTC a $400-\mathrm{km}$ band of light winds and deep convection associated with the Intertropical Convergence Zone (ITCZ) was encountered. South of the ITCZ at 0020 UTC some isolated convection was observed as evidenced by the high $\mathrm{CW}$ lidar backscatter and high relative humidity values at aircraft level. After this period (0100 UTC), winds become southerly at less than $5 \mathrm{~m} \mathrm{~s}^{-1}$ which generally prevailed until the end of the flight. Equator crossing occurred at 0000 UTC. Figures $3 a-3 c$ show the aerosol backscatter coefficient computed from the FSSP size data for the wavelengths $1.06,9.11$, and $9.25 \mu \mathrm{m}$, respectively. Very little GSFC lidar data were available for a meaningful comparison at $0.53 \mu \mathrm{m}$, and the $10.59-\mu \mathrm{m} \mathrm{CW}$ lidar data were very noisy; consequently these data were not used.

$1.06 \mu \mathrm{m} . \beta_{(\mathrm{FSSP}, 1.06)}$ and $\beta_{(\mathrm{GSFC}, 1.06)}$ data are shown in Figure 3a. Over the time period 2120-2300 UTC, temporal and absolute backscatter trends are followed reasonably well even below the GSFC lidar threshold line. The two peaks seen in the $\beta_{\text {(GSFC, 1.06) }}$ data at 2145 and 2200 UTC were the result of the 

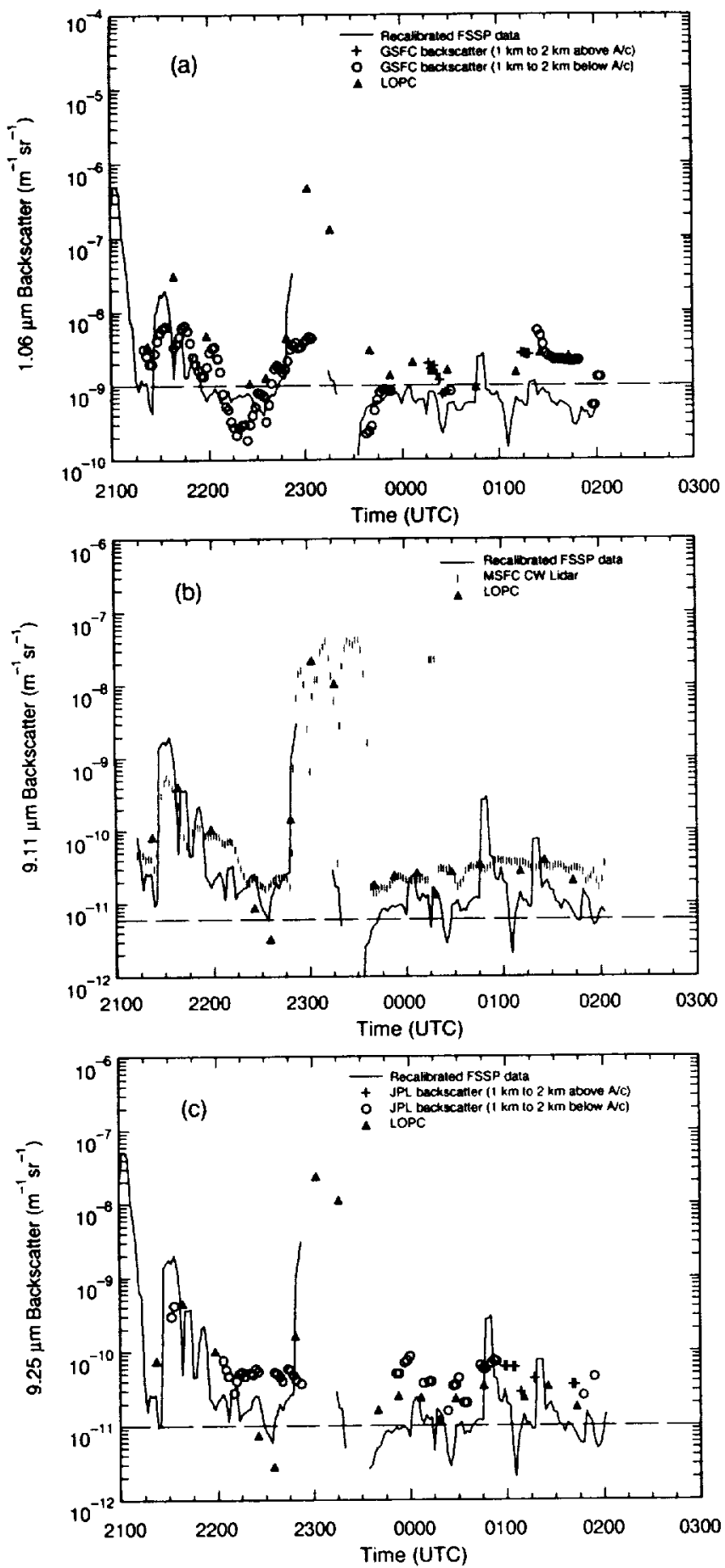

Figure 3. Temporal variation of measured and modeled aerosol backscatter coefficient $(\beta)$ during flight 6 for wavelengths (a) $1.06 \mu \mathrm{m}$, (b) $9.11 \mu \mathrm{m}$, and (c) $9.25 \mu \mathrm{m}$. Dashed line in each panel represents the lidar detection threshold.

top portions of an aerosol plume (seen in the time-altitude backscatter cross-section image) entering the averaging region below the aircraft. Backscatter values within these plumes were about $2-3 \times 10^{-8} \mathrm{~m}^{-1} \mathrm{sr}^{-1}$. This plume originated from the marine boundary layer (MBL) near the ITCZ (latitude

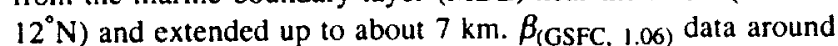
2220 to 2240 were heavily edited to remove cloud returns and are below the threshold line which resulted in some scatter in the data.
For the period $2340-0030$ UTC the $\beta_{\text {(GSFC, 1.06) data are }}$ scattered to either side of the FSSP-derived data. The timealtitude $\beta_{\text {(GSFC, 1.06) }}$ cross-section image indicates a region of aerosol inhomogeneity and editing of cloud returns. In the third comparison period (0110-0145 UTC), $\left.\beta_{(\mathrm{GSFC}}, 1.06\right)$ data show a similar temporal trend to the $\beta_{(\mathrm{FSSP} .1 .06)}$ data but are about a factor of 5 higher. In this case the nadir GSFC data were available for averaging over only the first $0.25 \mathrm{~km}$ from $1 \mathrm{~km}$ below the aircraft instead of the usual $1-\mathrm{km}$ depth. Having a smaller number of points in the averaging may have contributed to a small part of this difference, although the points included were nearest to the flight level. The timealtitude $\beta_{\text {(GSFC, 1.06) }}$ cross-section image for this period does indicate a very uniform aerosol backscatter. However, this does not rule out the existence of spatial aerosol inhomogeneity between flight level and $1 \mathrm{~km}$ below. The LOPC differential backscatter plot (not shown) for particle diameter range 0.16 $0.35 \mu \mathrm{m}$ indicated only $25 \%$ contribution to the total $1.06-\mu \mathrm{m}$ backscatter. On the other hand, the condensation nuclei ( $\mathrm{CN}$ ) plot (also not shown) also indicated an increase in the ambient $\mathrm{CN}$ from 400 to $1200 \mathrm{~cm}^{-3}$ with very little refractory $\mathrm{CN}$ present, but at the most, this would imply only an additional small increase in differential $\beta$ assuming no aerosol composition changes. The $\beta_{(\mathrm{LOPC}, 1.06)}$ data showed best agreement here when an acid sulfate composition is selected.

$9.11 \mu \mathrm{m}$. Figure $3 \mathrm{~b}$ shows the aerosol backscatter coefficients derived from FSSP size distribution data for 9.11- $\mu \mathrm{m}$ wavelength using refractive index data derived from the LOPC thermally segregated size distribution data, along with the corresponding $\mathrm{CW}$ lidar and LOPC-derived aerosol backscatter data. In the early period from 2115 UTC until cirrus cloud was encountered at 2250 UTC, the $\beta_{\text {(FSSP. 9.11) data closely follow }}$ the $\beta_{(\mathrm{CW}, 9.11)}$ data except in the period 2200 to 2220 UTC. The underestimate in $\beta_{\text {(FSSP, 9.11) data for these low values }}$ occurred consistently in these analyses as well as in other analyses not reported here. After the cirrus cloud region the $\beta_{(\mathrm{CW}, 9.11)}$ data lay above the $\beta_{\text {(FSSP, 9.11) }}$ data for the rest of the flight except at 0050 and 0120 and showed much less temporal variation. The $\beta_{1 \mathrm{LOPC}, 9.11)}$ data followed much closer to the $\beta_{(\mathrm{CW}, 9.11)}$ data in absolute levels and also exhibited less temporal variation than the $\beta_{\text {(FSSP, 9.11) data. One of the rea- }}$ sons for the differences seen here is the count statistics for FSSP size data above $1 \mu \mathrm{m}$ diameter. Particles in the $0.8-$ to $3-$ $\mu \mathrm{m}$-size range dominate the backscatter in these infrared wavelengths [Srivastava et al., 1992], and so there will be the tendency to underestimate the computed backscatter if these particles are not adequately sampled. Using FSSP averaging times greater than $100 \mathrm{~s}$ would not improve this situation: the FSSP would have to actually sample for much longer than $100 \mathrm{~s}$ to improve the large particle count statistics, or the sampling procedure would have to be modified to concentrate these particles into the FSSP sampling volume. On the other hand, the LOPC, already equipped with virtual impactor and using sampling times of several minutes, had better counting statistics (see section 4.1). Agreement between $\beta_{(\mathrm{CW},} 9.11$ ) and $\beta_{\text {(LOPC. } 9.11, \text { was very good in low backscatter conditions over }}$ the period 2335 to 0200 UTC. Except for the cirrus cloud period the aerosol composition derived from the LOPC data analysis is best represented by the acid sulfate composition over all size ranges (V. Srivastava et al., manuscript in preparation, 1995). The excursions in FSSP-derived $\beta$ at 0050 and 0120 UTC can be explained as follows: If the composition of large particles ( $>1 \mu \mathrm{m}$ ) over this period does not change, then the lidar and LOPC backscatter is expected to not show 
much variation. On the other hand, if the submicron particle composition changes, then the FSSP-derived backscatter could vary significantly because FSSP is only sampling this range of particles adequately and not the larger particles. For example, the submicron particles at 0050 and 0120 UTC may possess more ammonium sulfate which would result in a much higher backscatter, because of the higher imaginary component of the refractive index. Analysis of other GLOBE II flights revealed similar results (D. R. Cutten et. al., manuscript in preparation, 1995).

A value for the underestimated differential aerosol backscatter $\left(d \beta / d \log \left(D_{p}\right)\right)^{*} \Delta \log D_{p}$ over a given size range has been derived. On examining the $d n$ data for the $1-$ to $2-\mu \mathrm{m}$ size range (Figure 2), a deficiency factor of about 6 was estimated for the FSSP data. An average value of $d \beta / d \log \left(D_{p}\right)^{*} \Delta \log D_{p}$ for a weak acid sulfate aerosol is about $5 \times 10^{-12} \mathrm{~m}^{-1} \mathrm{sr}^{-1}$ and when multiplied by this deficiency factor, becomes $3 \times 10^{-11} \mathrm{~m}^{-1}$ $\mathrm{sr}^{-1}$. From Figure $3 \mathrm{~b}$ the average $\beta_{(\mathrm{FSSP}, 9.11)}$ value for the time period 0030-0155 UTC (excluding the two major peaks) was about $1 \times 10^{-11} \mathrm{~m}^{-1} \mathrm{sr}^{-1}$. Adding in the $d \beta / d \log \left(D_{p}\right)^{*} \Delta \log D_{p}$ value gives a new $\beta_{(\mathrm{FSSP}, 9.11)}$ value of $4 \times 10^{-11} \mathrm{~m}^{-1} \mathrm{sr}^{-1}$, which is much closer to the $\beta_{(\mathrm{CW}, 9.11)}$ data.

$9.25 \mu \mathrm{m}$. Figure $3 \mathrm{c}$ shows the comparison of $\beta_{(\mathrm{JPL}, 9.25)}$ data and $\beta_{\text {(FSSP, 9.11) }}$ data which indicated varied agreement along the flight. In the earlier part of the flight (2130-2250 UTC) the $\beta_{(\mathrm{JPL}, 9.25)}$ data were generally above the $\beta_{(\mathrm{FSSP}, 9.11)}$ data with an ill-defined temporal trend. Cirrus cloud which extended down to flight level was responsible for the high backscatter in the period 2250 to 2340 UTC. For the time period 2350 to 0200 UTC again the $\beta_{\text {(FSSP, 9.11) }}$ data were generally below the $\beta_{(\mathrm{JPL}, 9.25)}$ data. The time-altitude $\beta_{(\mathrm{JPL}, 9.25)}$ cross-section image indicated fairly uniform backscatter within the averaging region with several very low backscatter areas around 0030 UTC. Apart from the low $\beta$ regions at 0030 the $\beta_{(\mathrm{JPL}, 9.25)}$ data follow the $\beta_{(\mathrm{CW}, 9.11)}$ data. For the same reason discussed above, poor count statistics for large particles are mostly responsible for the FSSP underestimating the backscatter, whereas the $\beta_{(\mathrm{LOPC}, 9.11)}$ data, however, are in closer agreement with the $\beta_{(\mathrm{JPL}, 9.25)}$ data.

\subsection{Japan to Hawaii Transit Flight}

Flight details. Flight 14 covered the leg from Tokyo, Japan, to Honolulu, Hawaii (see Figure 1), on June 3-4, 1990, from 2255 to 0530 UTC with a constant pressure altitude maintained at $8.5 \mathrm{~km}$ for the duration of the flight. Detailed meteorological conditions encountered along the flight are given by E. W. McCaul et al. (manuscript in preparation, 1995) and only a brief synopsis is given here. The flight began near a midlatitude jet located south of Japan, and after several hours into the flight, several shortwave troughs were traversed. During this period, cirrus cloud was generally located above the aircraft but was at flight level during the periods 2300-0000 UTC and 0150-0215 UTC. On the approach to Hawaii, subtropical high conditions prevailed with little cloud present at or near flight level. Figures $4 a-4 e$ show the aerosol backscatter coefficient computed from the FSSP size data for the wavelengths $0.53,1.06,9.11,9.25$, and $10.59 \mu \mathrm{m}$, respectively, along with the lidar and LOPCderived $\beta$ data. No lognormal fitting was done to the FSSP size data for the periods cirrus cloud was traversed. Several other small gaps are seen in the plot where the fitting could not be done reliably.

First, the discussion will briefly dwell on the composition of aerosol particles encountered during this flight. A more
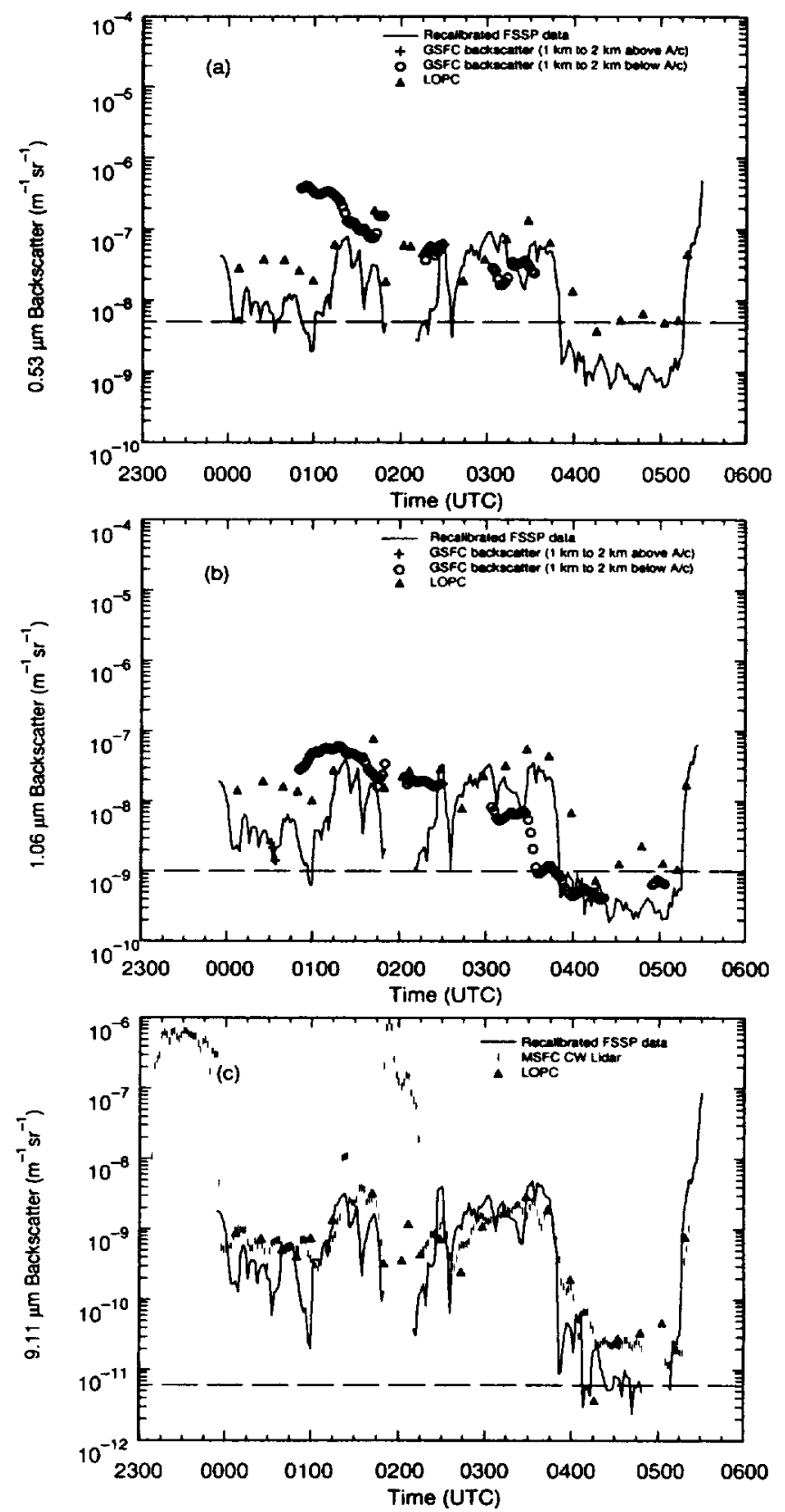

Figure 4. Temporal variation of measured and modeled aerosol backscatter coefficient $(\beta)$ during flight 14 for wavelengths (a) $0.53 \mu \mathrm{m}$, (b) $1.06 \mu \mathrm{m}$, (c) $9.11 \mu \mathrm{m}$, (d) 9.25 $\mu \mathrm{m}$, and (e) $10.59 \mu \mathrm{m}$. Dashed line in each panel represents the lidar detection threshold.

detailed discussion on the modeling of the aerosol composition encountered during this flight, using infrared aerosol backscatter data to constrain the physicochemistry model, will be published (V. Srivastava et al., manuscript in preparation, 1995). Both measured and derived aerosol backscatter for 9.11- $\mu \mathrm{m}$ and $10.59-\mu \mathrm{m}$ wavelengths (see Figures $4 \mathrm{c}$ and $4 \mathrm{e}$ ) indicated that for the initial portion of the flight up to about 0230 UTC (excluding the period of cirrus cloud), a partially ammoniated continental dust aerosol represented the particle regime. After 0230 UTC, varying amounts of ammonium sulfate, characteristic of an advected continental plume, were present, diluted with clean tropospheric air. During 0350-0515 UTC the aerosol was dominated by sulfuric acid with some par- 

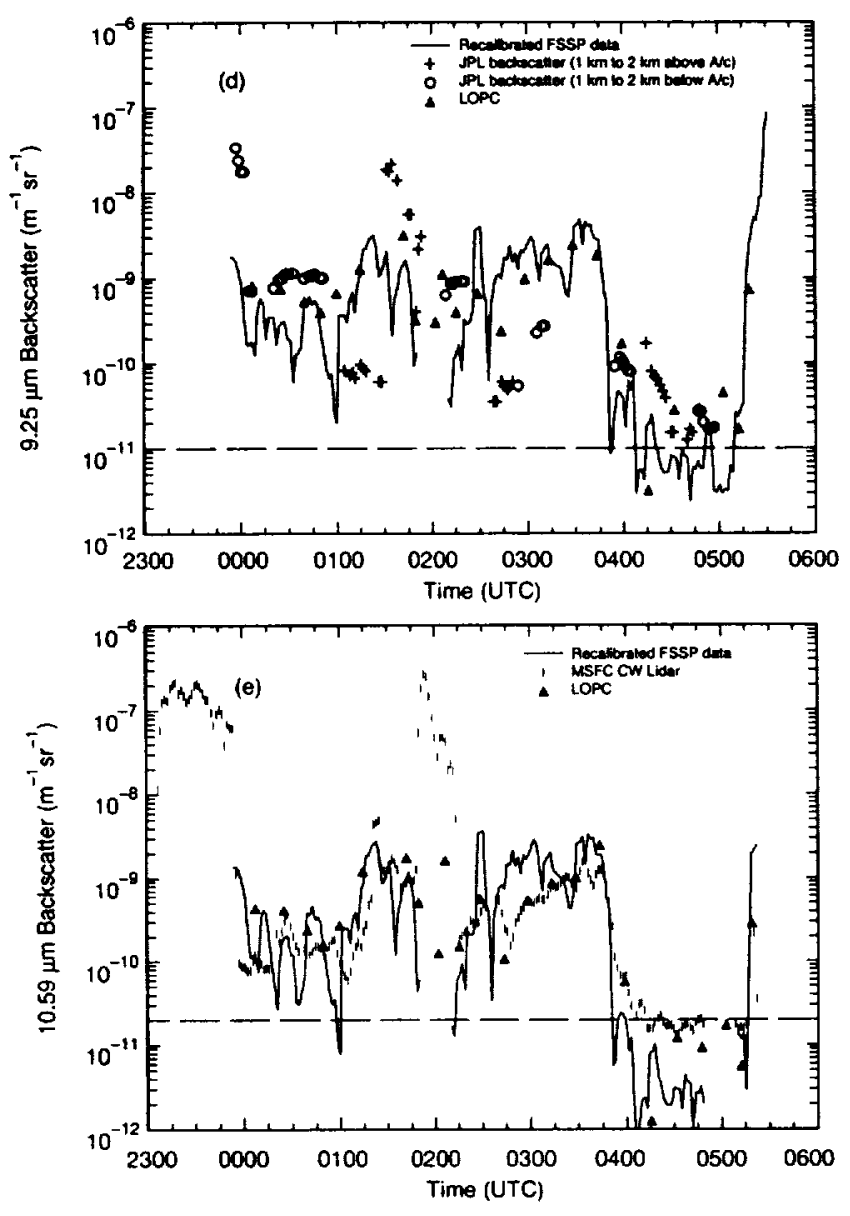

Figure 4. (continued)

tial ammoniation comfirmed by the $9.11-\mu \mathrm{m}$ and $10.59-\mu \mathrm{m}$ $\mathrm{CW}$ lidar $\beta$ data for this period as having a ratio near 2 . During the last period the composition is consistent with an aerosol type generally associated with low backscatter in the free troposphere of a subtropical high [Srivastava et al., 1995].

0.53 and $1.06 \mu \mathrm{m}$. The comparison of FSSP-derived $\beta$ data with GSFC $\beta$ data at these two wavelengths showed reasonable agreement over two portions of the flight, while several other regions showed large disagreement. One of the largest discrepancies occurred during 0050-0120 UTC where $\beta$ estimates from both the FSSP and the LOPC were initially much smaller than the GSFC data, especially at $0.53 \mu \mathrm{m}$, but gradually approached the GSFC data at both 0.53 and $1.06 \mu \mathrm{m}$ later in the period. Flight level volatility data initially showed a predominately refractory sootlike $\mathrm{CN}$ aerosol with little change in $\mathrm{CN}$ concentrations until later in the period. During this same period, LOPC data showed a systematic increase in larger particles most likely composed of mixed acid sulfates. However, up to $30 \%$ of the LOPC-derived $\beta$ values was contributed by particles between the LOPC threshold $(0.15 \mu \mathrm{m})$ and the FSSP threshold $(0.35 \mu \mathrm{m})$. GSFC data initially showed much higher $\beta$ at $0.53 \mu \mathrm{m}$ than at $1.06 \mu \mathrm{m}$. However, measured $\beta$ at $1.06 \mu \mathrm{m}$ increased steadily, while $\beta$ at $0.53 \mu \mathrm{m}$ decreased steadily. All of these trends are consistent with a systematic change in aerosol type from smaller particles early in the period to larger particles later in the period, both at and below flight level. Discrepancies between FSSP and GSFC $\beta$ values during this period were probably due to high concentrations of small particles below the FSSP detection threshold, combined with vertical gradients in a stratified plume such as might be expected in aged urban pollution downwind of Tokyo.

In the period 0145-0220 UTC the aircraft passed through some cloud as was evident from the FSSP size distribution image and $\mathrm{CW}$ lidar data plots. However, below the aircraft $(>1 \mathrm{~km})$ there was no evidence of returns from cloud in the pulsed lidar backscatter data. Therefore comparisons of the FSSP data with the GSFC lidar data are not meaningful because they were sampling different scattering media. The LOPCderived $\beta$ show some agreement with the pulsed lidar data probably because the cloud droplets impacted on the walls of the plumbing or evaporated before they reached the LOPC sample volume.

For the last period (0300 to 0515 UTC) the $1.06-\mu \mathrm{m}$ comparison indicated reasonable agreement between GSFC- and FSSP-derived $\beta$ data except for the fall in $\beta$ occurring at 0330 UTC. The 1.06- $\mu \mathrm{m}$ GSFC time-altitude cross-section backscatter image data for this flight indicated a 300 - to 500-m-thick aerosol layer present $1-2 \mathrm{~km}$ below the aircraft flight level and its upper interface inclined upward in the flight direction. As the aircraft progressed along the flight track, the nadirviewing GSFC lidar was probing less and less of this layer resulting in a lower averaged $\beta$ leveling out near the threshold line. Once the aircraft cleared this high-aerosol backscatter regime, the two $\beta$ estimates merge in the low backscatter regime even though that the GSFC $\beta$ data fall below the threshold level for this wavelength. The short comparison around 0500 UTC, still in this low-level backscatter regime, indicated that the GSFC and LOPC $\beta$ data lie above the FSSPderived $\beta$ data before aircraft descent. This difference can be accounted for by the large contribution $(>20 \%)$ to $\beta$ from the 0.16 - to $0.35-\mu \mathrm{m}$-diameter particles that the LOPC sensor was able to measure. The $0.53-\mu \mathrm{m}$ FSSP-derived and GSFC $\beta$ data comparison covered a much shorter period (0300 to 0330 UTC) and showed agreement only in the latter part of the period before the large drop when entering the subtropical high region. LOPC differential backscatter data for this period indicated only a small contribution $(<15 \%)$ to $\beta$ from the particles in the size range 0.16 to $0.35 \mu \mathrm{m}$ diameter. In both the 0200 and the 0300 hour periods, ratios of GSFC 0.53 - and $1.06-\mu \mathrm{m}$ backscatter data indicated that the wavelength exponent fluctuated between $I$ and 2.3 which indicated the existence of large and moderate size particles, respectively.

9.11 and $10.59 \mu \mathrm{m}$. In these wavelength comparisons (Figures $4 \mathrm{c}$ and $4 \mathrm{e}$ ) both the $\mathrm{CW}$ lidar and the FSSP-derived $\beta$ were obtained at flight level, thus minimizing the effects of aerosol inhomogeneities. In this flight the large temporal trends are closely matched although smaller changes are not followed as well. Some of the smaller FSSP-derived $\beta$ data fluctuations arise from count-sampling statistics in a small sampling volume, whereas the $\mathrm{CW}$ lidar does not necessarily exhibit such fluctuations because of its much larger sampling volume (a factor of $\approx 6 \times 10^{5}$ larger). On longer timescales, measured and modeled $9.11-\mu \mathrm{m} \beta$ values generally agree within a factor of 2 except for a factor of 3 discrepancy during the period 0415-0445 UTC. A similar comment can be made for the $10.59-\mu \mathrm{m}$ wavelength comparison (Figure $4 \mathrm{e}$ ). Note that the period 0000-0100 UTC showed better absolute agreement at $10.59 \mu \mathrm{m}$ than $9.11 \mu \mathrm{m}$ although a different temporal trend was evident in the $10.59-\mu \mathrm{m} \mathrm{CW}$ lidar $\beta$ data.

The biggest difference in the 9.11 - and $10.59-\mu \mathrm{m} \beta$ data occurred at 0415-0445 UTC during the traversing of the sub- 
tropical high on the approach to Hawaii. This can be explained as follows: The aerosol backscatter in this period was dominated by a low concentration of particles around $\mathrm{l} \mu \mathrm{m}$ diameter which the FSSP was unable to sample adequately but were sampled more accurately by the $\mathrm{CW}$ lidar beam because of the five order increase in sampling volume. The LOPC-derived $\beta$ data are in good agreement with the $\left.\beta_{(\mathrm{CW}} .9 .11\right)$ and $\beta_{(\mathrm{CW}, 10.59)}$ data. The false color size-time cross-section plot of $d n / d \log \left(D_{p}\right)$ for this flight (see Plate la) confirms that the FSSP concentrations above $1 \mu \mathrm{m}$ diameter were almost neglible during this time period, while the LOPC concentrations were as high as $0.01 \mathrm{~cm}^{-3}$. A calculation of 9.11- $\mu \mathrm{m}$ differential backscatter coefficient, $d \beta / d \log \left(D_{D}\right)^{* \Delta}$ $\log D_{p}$ (as for flight 6 infrared $\beta$ data), confirmed this finding, yielding a corrected $\beta$ value around $2.3 \times 10^{-11} \mathrm{~m}^{-1} \mathrm{sr}^{-1}$ for this period. A deficiency factor of 2 in $d n$ was derived from the FSSP-LOPC $d n$ plot. Aerosol composition for this region indicated relatively more acidic sulfate aerosol present than in the case examined in flight 6 , resulting in a slightly higher $d \beta / d \log \left(D_{p}\right) * \Delta \log D_{p}$ value for the $1-$ to $2-\mu \mathrm{m}$ size range (V. Srivastava et al., manuscript in preparation, 1995).

$9.25 \mu \mathrm{m}$. Comparison of $\beta_{(\mathrm{FSSP}, 9.11)}$ and $\beta_{(\mathrm{JPL}, 9.25)}$ data (Figure $4 \mathrm{~d}$ ) showed much more variability than any of the other wavelengths compared in this flight. Some of this variability arose from aerosol inhomogeneity near the flight path because the $\beta_{(\mathrm{JPL}, 9.25)}$ data are measured either $1 \mathrm{~km}$ below or above the aircraft flight level. Lidar backscatter near 0000 UTC was due to a high backscatter layer in the 6- to $7-\mathrm{km}$ altitude region. In the time period 0130-0145 UTC the high $\beta$ values are due to cirrus occasionally extending down nearly to flight altitude. Thus the situation at flight level was not always representative of what the JPL lidar was seeing. JPL trends here also tend to correlate with GSFC trends, thus supporting aerosol inhomogeneity. The closest agreement is for the period $0400-0500$ UTC where $\beta$ showed an overall trend to lower values.

To summarize, the infrared wavelength-measured and modeled comparisons of aerosol backscatter near or above $10^{-9}$ $\mathrm{m}^{-1} \mathrm{sr}^{-1}$ showed reasonable agreement. Below this $\beta$ level, agreement is not so good. In most cases, poor count statistics for particles greater than about $1.0 \mu \mathrm{m}$ diameter are contributing to a lower and more fluctuating FSSP-derived $\beta$ in lowaerosol backscatter regions.

\subsection{Aerosol Backscatter Coefficient Comparisons: Other Transit Flights}

In this section, three other transit flights are examined: two (flights 8 and 10) cover the southern hemisphere, while the third (flight 12) is another meridional flight across the equatorial region. Data from these flights have been combined to provide cross plots of FSSP-derived and lidar-derived $\beta$ data rather than the time-series plots shown in the previous section. LOPC-derived $\beta$ are not included in these plots because of the much longer averaging time used to sample the aerosol and variations in $\mathrm{CW}$ lidar $\beta$ would be smoothed out. Data from flights 6 and 14 have also been included in the plots for comparison purposes. Any cloud returns from the $\mathrm{CW}$ lidars were excluded and all remaining data smoothed with a 300 -s running average. Flight details are as follows:

Flight 8. This flight flew southwestward from Papeete, Tahiti, to Christchurch, New Zealand, on May 23-24 beginning at 2258 and ending at 0524 UTC. Flight altitude varied between 8 and $12 \mathrm{~km}$. Scattered convection gradually increased in coverage early in the flight until at 0040 UTC the aircraft was forced to climb to $12 \mathrm{~km}$ to fly over the storms. At about 0230 UTC the aircraft descended to $9 \mathrm{~km}$ and traversed a region suggestive of a midtropospheric front (latitude $33^{\circ} \mathrm{S}$ ). After descending further to $8 \mathrm{~km}$ near 0300 UTC, the aircraft entered into a region of anticyclonic flow. After 0300 UTC the aircraft began to overfly increasing amounts of lower-tropospheric convection and was forced at 0430 UTC to ascend to $12 \mathrm{~km}$ near latitude $44^{\circ} \mathrm{S}$. Westerly winds of the order of $60 \mathrm{~m} \mathrm{~s}^{-1}$ were encountered in a jet core at this altitude shortly before landing.

Flight 10. This flight went from Christchurch, New Zealand, to Melbourne, Australia, on May 28 starting at 0022 and ending at 0805 UTC. Altitude varied from about $7.5 \mathrm{~km}$ to $8.5 \mathrm{~km}$ with the lowest level being at the extreme latitude of $56^{\circ} \mathrm{S}$ at 0330 UTC. Low-level cloudiness was widespread in this flight along with some shallow convection. Near latitude $55^{\circ} \mathrm{S}$ a $70 \mathrm{~m} \mathrm{~s}^{-1}$ westerly jet was encountered before landing.

Flight 12. This flight commenced at Darwin, Australia (0058 UTC), and terminated at Tokyo, Japan, on May 31 (0723 UTC). At around 0340 UTC a clean $\approx 200-\mathrm{km}$-wide $\mathrm{N}-\mathrm{S}$ midtropospheric air mass was encountered just north of the ITCZ. However, by 0430 UTC the air mass had changed over to a predominantly continental air mass containing Asian dust in a low humidity environment by which time a strong westerly upper level jet was encountered. The plume persisted until the descent into Tokyo. This dust feature was strongly evident in the time-altitude backscatter cross-section images for the GSFC and JPL pulsed lidars (E. W. McCaul et al., manuscript in preparation, 1995) which also includes a more detailed description of the meteorological conditions encountered.

9.11 and $10.59 \mu \mathrm{m}$. The $9.11-$ and $10.59-\mu \mathrm{m}$ data (Figures $5 \mathrm{a}$ and $5 \mathrm{~b}$ ) at $\beta$ values above $\approx 2-3 \times 10^{-10} \mathrm{~m}^{-1} \mathrm{sr}^{-1}$ are clustered either side of the $1: 1$ line, which indicates that the count statistics for the FSSP appear adequate for these backscatter values. However, there is still a wide range of scatter in this backscatter region which is probably the result of different factors. As noted earlier, the disparity between the sampling volumes of the FSSP and CW lidar is quite large and probably highlights aerosol inhomogeneities resulting from refractive index changes on a small scale. Furthermore, the FSSP sampling volume, although located on the same side of the aircraft as the $\mathrm{CW}$ lidar sampling volume, did not fall within the lidar sampling volume.

For $\beta<10^{-10} \mathrm{~m}^{-1} \mathrm{sr}^{-1}$ data points at the two wavelengths for all flights lie mostly above the $1: 1$ line (Figures $5 \mathrm{a}$ and $5 \mathrm{~b}$ ) with the most deviation away from this line at the very low levels, confirming the earlier conclusion that poor FSSP count statistics imply lower FSSP-derived backscatter values. Most data from flights 8 and 10 show aerosol backscatter lying within this region of low backscatter. The shaded band in the two figures indicates the range of FSSP-derived $\beta$ when only one count is registered in one of the FSSP size channels between 0.7 - and 1.3- $\mu \mathrm{m}$ particle diameter; all other channels are assigned zero counts. Note that these band limits depend on the refractive index of the aerosol being sampled and the FSSP calibration constant. Therefore the shaded band represents an "effective backscatter detection" threshold for the FSSP in regions with occasional large particles, roughly analogous to the more rigorous detection thresholds for each of the lidars. The shaded area is representative for flight 14 and indicates that the scatter of backscatter at these low values can be mostly attributable to only a few counts being available. One 


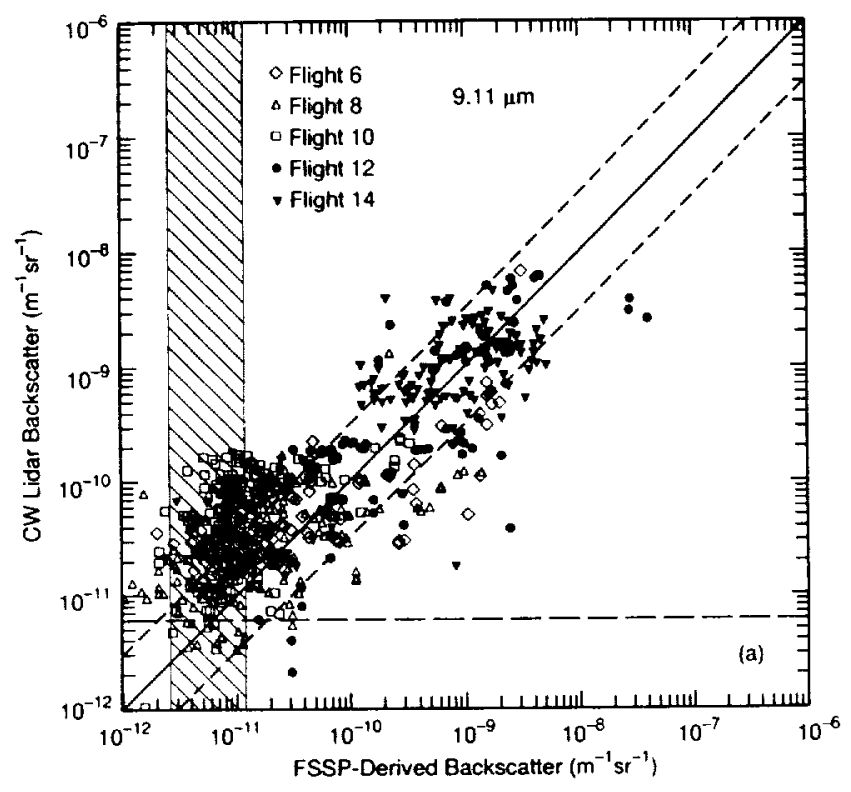

\subsection{Frec Troposphere Background Aerosol Mode}

Finally, all the $\beta_{(\text {FSSP, }}$ 9.11) and $\beta_{(\mathrm{CW}, 9.11)}$ data at flight level and $\beta_{(\mathrm{JPL}, 9.25)}$ data within $1-2 \mathrm{~km}$ of the aircraft (for all five flights) are replotted in the form of three histograms (Figures $6 a-6 c$ ). Each plot represents data that has been further subdivided into northern and southern hemisphere categories, and Table 3 summarizes the low and high $\beta$ modes associated
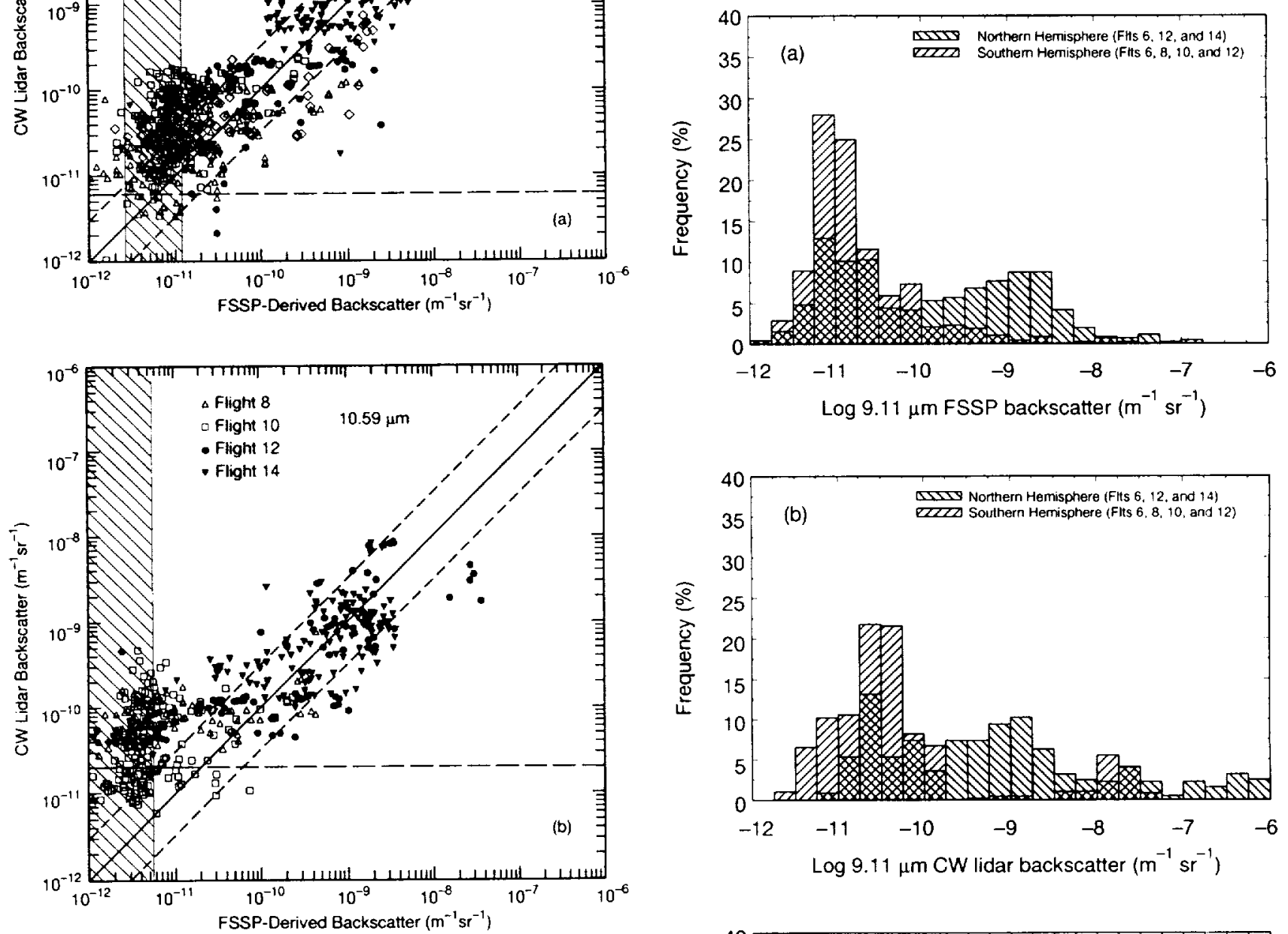

Figure 5. Cross plots of lidar-derived versus FSSP-derived aerosol backscatter coefficient $(\beta)$ at (a) $9.11 \mu \mathrm{m}$ and (b) 10.59 $\mu \mathrm{m}$ for flights $6,8,10,12$, and 14 . Horizontal dashed line in each panel represents lidar detection threshold, while diagonal dashed line pair lies at \pm 3 factor from the $1: 1$ line. Shaded area represents range of FSSP-derived $\beta$ for one bin count in size bins between 0.7 and $1.3 \mu \mathrm{m}$ (see text).

should also note for flights 8 and 10 that there are a few 9.11 and $10.59-\mu \mathrm{m}$ backscatter data falling below the $\mathrm{CW}$ lidar threshold line and the $1: 1$ line, whereas for flight 12 data, this is not the case. Possible reasons are as follows: First, any data below the threshold line should be considered noisy and have a large error [Rothermel et al., 1995b]: flight 10 data at 10.59 $\mu \mathrm{m}$, relatively, having the most points below the threshold line. Second, those data points below the $1: 1$ line and above the CW lidar threshold line are probably due to a combination of spatial variability (since sensor sampling volumes differ by a factor of $6 \times 10^{5}$ (Table 1)) and sampling statistics.

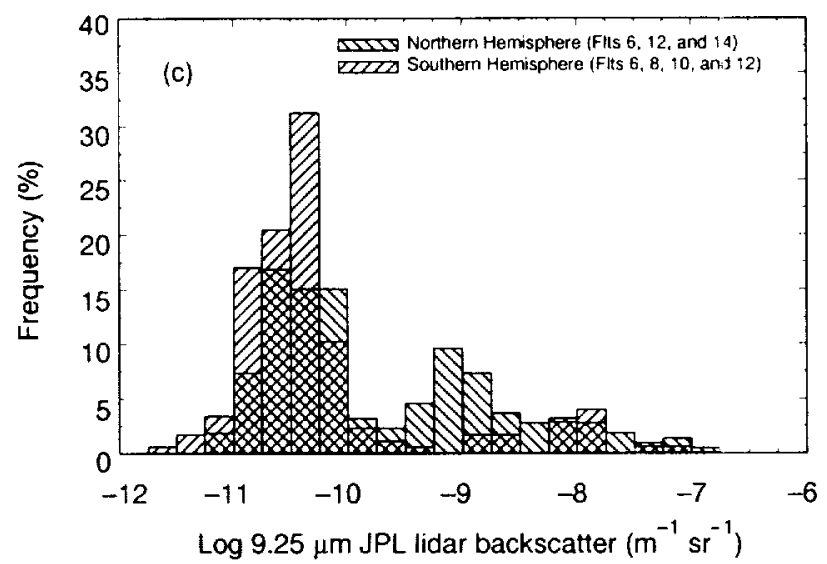

Figure 6. Frequency histograms of mid-infrared aerosol backscatter coefficient for the northern and southern hemispheres derived from (a) FSSP, (b) continuous wave (CW) lidar, and (c) Jet Propulsion Laboratory pulsed lidar sensors, respectively. The FSSP and CW lidar data are for flight level; JPL data are within $1-2 \mathrm{~km}$ above and below flight level. 
Table 3. List of Modes Seen in Free Troposphere Infrared Aerosol Backscatter Histograms

\begin{tabular}{|c|c|c|c|c|c|}
\hline & Sensor & $\begin{array}{c}\text { Northern } \\
\text { Hemisphere } \\
\text { (Low } \beta \text { Mode) }\end{array}$ & $\begin{array}{c}\text { Northern } \\
\text { Hemisphere } \\
\text { (High } \beta \text { Mode) }\end{array}$ & $\begin{array}{c}\text { Southern } \\
\text { Hemisphere } \\
\text { (Low } \beta \text { Mode) }\end{array}$ & $\begin{array}{c}\text { Southern } \\
\text { Hemisphere } \\
\text { (High } \beta \text { Mode) }\end{array}$ \\
\hline GLOBE II & $\begin{array}{l}\text { FSSP-derived } \beta \\
(9.11 \mu \mathrm{m})\end{array}$ & $1 \times 10^{-11}$ & $1 \times 10^{-9}$ & $1 \times 10^{-11}$ & - \\
\hline GLOBE II & $\begin{array}{c}\text { CW lidar } \beta \\
(9.11 \mu \mathrm{m})\end{array}$ & $3 \times 10^{-11}$ & $1 \times 10^{-9}$ & $3 \times 10^{-11}$ & weak \\
\hline GLOBE II & $\begin{array}{l}\text { JPL lidar } \beta \\
(9.25 \mu \mathrm{m})\end{array}$ & $3 \times 10^{-11}$ & $8 \times 10^{-10}$ & $4 \times 10^{-11}$ & weak \\
\hline GLOBEI & $\begin{array}{l}\text { FSSP-derived } \beta \\
(\approx 10 \mu \mathrm{m})\end{array}$ & $1 \times 10^{-11}$ & - & $3 \times 10^{-11}$ & - \\
\hline
\end{tabular}

with each histogram. Each histogram for the northern hemisphere clearly shows two modes with an intermodal gap near $1 \times 10^{-10}$. The high-backscatter mode in all plots has a common center around $1 \times 10^{-9} \mathrm{~m}^{-1} \mathrm{sr}^{-1}$. However, the FSSPderived low backscatter or background mode $\left(1 \times 10^{-11} \mathrm{~m}^{-1}\right.$ $\mathrm{sr}^{-1}$ ) is clearly lower than the corresponding mode in the other two northern hemisphere histograms. A similar shift is also seen in the southern hemisphere histogram plots. The background modes $\left(3 \times 10^{-11} \mathrm{~m}^{-1} \mathrm{sr}^{-1}\right)$ for aerosol backscatter measured with the CW Doppler and JPL lidars are in qualitative agreement with background modes observed in other $\mathrm{CO}_{2}$ lidar aerosol backscatter data obtained in the free troposphere [Rothermel et al., 1989]. Hence, the lower value for the background mode observed for the FSSP-derived data must be the result of the FSSP sensor underestimating the $0.8-$ to $3-\mu \mathrm{m}$ diameter particles as reported earlier. The factor of 3 is also the value found for regions of flights 6 and 14 where $d \beta / d \log$ $\left(D_{p}\right) * \Delta \log \left(D_{p}\right)$ over this size range needed to be increased. A similar histogram of acrosol backscatter $(\approx 10-\mu \mathrm{m}$ wavelength) has been presented by Pueschel et al. [1994] derived from a number of randomly selected FSSP size distributions measured in GLOBE I. (These calculations were based on original Latex sphere calibration for the FSSP and an ammonium sulfate aerosol refractive index.) In that study the northern and southern hemisphere modes were located at $1 \times 10^{-11} \mathrm{~m}^{-1} \mathrm{sr}^{-1}$ and $3 \times 10^{-11} \mathrm{~m}^{-1} \mathrm{sI}^{-1}$, respectively: the latter mode is a factor of 3 higher than reported here for the 1990 southern hemisphere data. Using the $\beta$ correction factor of 3 estimated earlier. Pueschel's background modes for the northern and southern hemispheres become $3 \times 10^{-11}$ and $6 \times 10^{-11} \mathrm{~m}^{-1} \mathrm{sr}^{-1}$, respectively. However, since Pueschel et al.'s $\beta$ calculations are not based on an acid sulfate aerosol and wavelength is higher than used here, their background mode would be enhanced by $20-30 \%$. The higher-backscatter mode seen in the southern hemisphere during GLOBE I is similar to that measured with the other lidars during this austral 1989 spring mission. The northern hemisphere FSSP-derived background modes, however, are now the same.

The upper mode at $1 \times 10^{-9} \mathrm{~m}^{-1} \mathrm{sr}^{-1}$ present in the northern hemisphere (Figures $6 a-6 c$ ) is mostly the result of aerosol backscatter measured during flight 14 with a small contribution from the dust region encountered in flight 12 . There was no contribution to this mode from flight 6 . The corresponding $\beta_{(\text {L.OPC, 9.11) histogram (not shown) covering the northern }}$ hemispheric region confirmed that sulfate aerosols, possibly mixed or coated with dust, contributed significantly to the backscatter in this mode. Note, however, that this mode was very weak in the southern hemisphere.

\section{Conclusions}

One of the significant conclusions from this work is that when the FSSP optical particle counter is used with short sampling periods $(<10 \mathrm{~s})$ in clean atmospheric conditions, it underestimated acrosol particle concentrations within the size range 0.8 to $3.0 \mu \mathrm{m}$ diameter. Particle counts within a particular size bin should conform to Poisson statistics if they are to be representative of the aerosol, which was not the case for size bins above $0.8 \mu \mathrm{m}$ diameter because of the small sample volume. Evidence for undercounting was confïrmed by (1) direct comparison of $d n$ averaged over selected time periods and integrated over several size ranges for FSSP and LOPC (with virtual impactor) and (2) comparison of infrared acrosol backscatter estimate at flight level measured with $\mathrm{CW} \mathrm{CO}_{2}$ lidars and derived from the FSSP. $\beta_{F S S P}$ data are underestimated below $10^{-10} \mathrm{~m}^{-1} \mathrm{sr}^{-1}$ at wavelengths between 9.11 and 10.59 $\mu \mathrm{m}$ because this is the size range which contributes most to the infrared acrosol backscatter. Backscatter derived from the FSSP have been estimated to be as much as a factor of 3 too low when backscatter falls between $10^{-11} \mathrm{~m}^{-1} \mathrm{sr}^{-1}$ and $10^{-10} \mathrm{~m}^{-1}$ $\mathrm{sr}^{-1}$. The large scatter seen in the $\beta_{F S S P}$, data can also be attributed to insufficient counts in the $0.8-$ to $3.0-\mu \mathrm{m}$-diameter size range. On the other hand, LOPC (VI) provided better agreement in this backscatter range. This is because the LOPC had a net gain over the FSSP in this size range from the use of a virtual impactor and larger sampling volume.

For $\beta>10^{-10} \mathrm{~m}^{-1} \mathrm{sr}^{-1}$ the agreement between the FSSPderived and flight level lidar data is better because FSSP count statistics have greater statistical significance, even though some of the data were noticeably scattered. The scatter likely arises from the large $\mathrm{CW}$ lidar sampling volume exhibiting acrosol microphysics variations (from small refractive index changes) within the volume that causes aerosol backscatter to fluctuate. CW lidar acrosol backscatter close to $10^{-11} \mathrm{~m}^{-1} \mathrm{sr}^{-1}$ showed better agreement with the FSSP-derived data because particles smaller than $\mathrm{I} \mu \mathrm{m}$ contribute most to the infrared backscatter under these conditions and the FSSP had reasonable count statistics for these size channels. This conclusion about underestimating particles in the $0.8-$ to $3-\mu \mathrm{m}$ size range means that to adequately obtain a representative size distribution one has to either increase the FSSP sampling time considerably or devise some means of concentrating these particles into the FSSP sampling volume to maintain short sampling times. One would still need to apply an analytically fitted lognormal curve to the data to reduce the influence of multivalued bin counts.

The comparison of the FSSP-derived and GSFC lidar 0.53 and $1.06-\mu \mathrm{m}$ acrosol backscatter indicated that the FSSP- 
derived data had generally underestimated the lidar data as expected. The $0.35-\mu \mathrm{m}$ size cutoff for the FSSP meant no particles were sampled adequately below this range, which contributes about $20 \%$ of the backscatter at $1.06 \mu \mathrm{m}$ and $33 \%$ at $0.53 \mu \mathrm{m}$ [Pusechel et al., 1994]. Many differences between the GSFC lidar and the FSSP-derived backscatter were attributable to acrosol inhomogeneity as sensor sampling volumes were not colocated, as well as there being a large disparity between the two sample volumes. The $\beta_{\text {(FSSP. 9.II) }}$

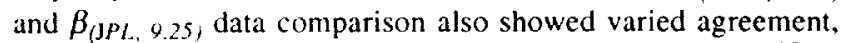
due in part to aerosol inhomogeneity. Again in the $10^{-10}$ to $10^{-11} \mathrm{~m}^{-1} \mathrm{sr}^{-1}$ region. $\beta_{(F S S P, 9.11)}$ data were noticeably lower due to the undercounting of particles in the $0.8-$ to $3-\mu \mathrm{m}$ diameter range.

In the two transit flight case studies presented here, LOPC microphysics supplemented by $\beta_{9.1} / \beta_{10.59}$ data indicated that a mixed phase of sulfuric acid and ammonium sulfate (acid sulfate) for the larger particles was the most likely aerosol composition present for most parts of the two flights. These particles contribute the most to the infrared aerosol backscatter. LOPC data also indicated that smaller particles in a subtropical environment are more likely to be externally mixed sulfuric acid and ammonium sulfate particles. The GSFC lidar data from the very early portion of flight 14 suggested the presence of very fine dust and/or sootlike particles in a possible pollution plume east of Tokyo, Japan.

The large continuous set of size distribution data obtained with the FSSP sensor enable statistics of infrared backscatter to be calculated in the midtropospheric atnosphere over the Pacific Ocean. Both the northern and the southern hemisphere data sets showed a major backscatter mode occurring around $3 \times 10^{-11} \mathrm{~m}^{-1} \mathrm{sr}^{-1}$ after a correction is made for large-particle underestimation. The mode is in close agreement to that reported in earlier work on the presence of an aerosol background mode in this region of the atmosphere.

Acknowledgments. The authors gratefully acknowledge the support of Ramesh Kakar. GLOBE program manager. NASA headquarters: Eugene McCaul Jr. for providing the meteorological summaries for the GLOBE flights and David Tratt. Sury Chudamani, and Diana Chambers for providing the JPL. GSFC. and MSFC lidar data, respectively. This work was supported under NASA cooperative agreement NCC8-22 and preceding contracts since 1990 .

IGCRE is jointly operated by the University of Alabama in Huntsville and the Universities Space Research Association.

\section{References}

Baker. W. E. et al., Lidar measured winds from space: An essential component for weather and climate prediction, Bull. Am. Meteorol. Sor.. 76, 869-888, 1995.

Baumgardner. D.. J. E. Dye. B. W. Gandrud, and R. G. Knollenberg. Interpretation of measurements made by the forward scattering spectrometer probe (FSSP-300) during the airborne Arctic stratosphere expedition, J. Geophys. Res., 97, 8035-8046, 1992.

Bowdle, D. A.. S. F. Williams, J. Rothermel, and J. E. Arnold, The GLObal Backscatter Experiment (GLOBE) Pacific survey mission. paper presented at the OSA Technology and Applications Topical Meeting on Coherent Laser Radar. Snowmass, Colo., 1991.

Clarke, A. D.. A thermo-optic technique for in situ analysis of sizeresolved aerosol physicochemistry. Atmos. Environ. 25A, 635-644. 1991.

Clarke, A. D., Atmospheric nuclei in the Pacific midtroposphere: Their nature. concentration. and evolution, J. Geophys. Res., 98, 20,633$20.647,1993$.
Horvath, H., R. L. Gunter, and S. W. Wilkison, Determination of the coarse mode of the atmospheric aerosol using data from a forwardscattering spectrometer probe, Aerosol Sci. Technol., 12, 964-980, 1990.

Jacobson, A. S., A. L. Berkin, and M. N. Orton, LinkWinds: Interactive scientific data analysis and visualization, Commun. $A C M, 37,42-52$. 1994.

Jarzembski, M. A., V. Srivastava, and D. M. Chambers, Lidar calibration technique using laboratory-generated aerosols, Appl. Opt., in press, 1995.

Kim, Y. J., Response of the Active Scattering Aerosol Spectrometer Probe (ASASP-100X) to particles of different chemical composition. Aerosol Sci. Technol., 22, 33-42. 1995.

Menzies, R. T., Doppler lidar atmospheric wind sensors: A comparative performance evaluation for global measurement applications from Earth orbit, Appl. Opt., 25, 2546-2553, 1986.

Menzies, R. T., and D. M. Tratt, Airborne $\mathrm{CO}_{2}$ coherent lidar for measurements of atmospheric aerosol and cloud backscatter, Appl. Opt., 24, 5698-5711, 1994.

Patterson. E. M., and D. A. Bowdle, Use of aerosol microphysical measurements to model IR backscatter in support of GLOBE, $J$. Geophys. Res., 96, 5315-5326, 1991.

Pinnick, R. G., D. M. Garvey, and L. D. Duncan, Calibration of Knollenburg FSSP lightscattering counters for measurement of cloud droplets, J. Appl. Meteorol., 20, 1049-1057, 1981.

Porter, J. A.. A. D. Clarke, and R. Pueschel. Aircraft studies of sizedependent aerosol sampling through inlets, J. Geophys. Res., 97. 3815-3824, 1992.

Prospero, J. M., R. J. Charlson, V. Mohnen, R. Jaenicke, A. C. Delany, J. Moyers, W. Zoller, and K. Rahn, The atmospheric aerosol system: An overview, Rev. Geophys., 21, 1607-1629.1983.

Pueschel, R. F., J. M. Livingston. G. V. Ferry, and T. E. DeFelice, Aerosol abundances and optical characteristics in the Pacific basin free troposphere. Atmos. Environ., 28, 951-960. 1994.

Rothermel. J., D. A. Bowdle. J. M. Vaughan, and M. J. Post. Evidence of a tropospheric acrosol background backscatter mode, Appl. Opt., 28 , 1040-1042. 1989.

Rothermel, J., D. A. Bowdle. and V. Srivastava, Mid-tropospheric aerosol backscatter background mode over the Pacific Ocean at 9.1 $\mu \mathrm{m}$ wavelenth, Geophys. Res. Lett., in press. $1995 \mathrm{a}$.

Rothermel J., D. M. Chambers, M. A. Jarzembski. V. Srivastava. D. A. Bowdle, and W. D. Jones, Signal processing and calibration of continuous-wave focused $\mathrm{CO}_{2}$ Doppler lidars for atmospheric backscatter measurement, Appl. Opt., in press. $1995 \mathrm{~b}$.

Spinhirne, J. D., S. Chudamani, and J. F. Cavanaugh, Visible and near IR lidar backscatter observations on the GLOBE Pacific survey missions (Preprints), in Seventh Symposium Metcorology Observation Instrumentation, pp. J26I-J264, Am. Meteorol. Soc., Boston, Mass.. 1991.

Srivastava, V., M. A. Jarzembski, and D. A. Bowdle, Comparison of calculated aerosol backscatter at 9.1 and $2.1 \mu \mathrm{m}$ wavelengths, Apll. Opt., 31, 1904-1906, 1992.

Srivastava. V., D. A. Bowdle, M. A. Jarzembski, J. Rothermel, D. M. Chambers, and D. R. Cutten. High-resolution remote sensing of atmospheric sulfate aerosols from $\mathrm{CO}_{2}$ lidar backscatter. (icophys. Res. Lett., 22, 2373-2376, 1995.

Strapp. J. W., W. R. Leaitch, and P. S. K. Liu, Hydrated and dried aerosol-size-distribution measurements from the Particle Measuring Systems FSSP-300 probe and the deiced PCASP-100X probe, $J$. Almos. Oceanic Technol.. 9, 548-555, 1992.

Tang, I, N., Deliquescence properties and particle size change of hygroscopic aerosols, in Generation of Aerosols, edited by $\mathrm{K}$. Willike, Ann Arbor Science Publishers Inc., ButterworthHeinemann, Newton, Mass., 1980.

D. R. Cutten and D. A. Bowdle, Institute for Global Change Research and Education and Earth System Science Laboratory, University of Alabama, Huntsville, AL 35899. 
R. F. Pueschel, NASA Ames Research Center, Moffett Field, CA 94035 .

V. Srivastava, Institute for Global Change Research and Education and Universities Space Research Association, Huntsville, AL 35806.

A. D. Clarke, School of Oceanography. University of Hawaii, Honolulu, HI 96822.

J. Rothermel, NASA Marshall Space Flight Center, Huntsville, AL 35812 .
J. D. Spinhime, NASA Goddard Space Flight Center, Greenbelt, MD 20771.

R. T. Menzies, Jet Propulsion Laboratory, Pasadena, CA 9/109.
(Received May 18, 1995; revised October 25, 1995; accepted October 25, 1995.) 
